MARIANA CASTRELLÓN PÉREZ*

Stanford University (Stanford, Estados Unidos)

\title{
Enfoque de género en la implementación de la Ley de Víctimas y Restitución de Tierras: una propuesta para la caracterización de las mujeres y niñas víctimas del conflicto armado en Colombia ${ }^{* * *}$
}

\author{
Gender perspective in the implementation of the Victims and Land \\ Restitution Law: a proposal for the characterization of women \\ and girls victims of armed conflict in Colombia
}

Enfoque de gênero na implementação da Lei de Vítimas e Restituição de Terras: uma proposta para a caracterização das mulheres e meninas vitimas do conflito armado na Colômbia

\footnotetext{
* Abogada y politóloga de la Universidad de los Andes. Actualmente, candidata a JSM en la Facultad de Derecho de la Universidad de Stanford. Correo electrónico: mariana2@stanford.edu

** Abogada y politóloga de la Universidad de los Andes de Bogotá, Colombia con maestría de protección de los derechos humanos de la Universidad Alcalá de Henares, España. Especialista en Derecho Penal de la Universidad del Externado de Colombia. Socia de Elementa, Consultoría en Derechos. Correo electrónico: catherineromero@elementa.co

${ }^{* * *}$ Este artículo es el resultado de una reflexión de una investigación realizada por el Centro de Investigaciones Sociojurídicas, CIJUS, en el 2013 bajo la dirección de Isabel Cristina Jaramillo para el PNUD. Las autoras agradecen a Magnolia Prada Rivas por su apoyo en la realización de la consultoría "Fortalecimiento de la Unidad Administrativa Especial para la Atención y Reparación Integral a las Víctimas y a la Unidad Nacional de Protección en la inclusión del enfoque de género y derechos de las mujeres en la gestión institucional y la sensibilización y capacitación de sus servidoras y servidores del proyecto PNUD/ 73012". Artículo de investigación recibido el 13/02/2016 y aceptado el 25/07/2016.
} 


\section{Cómo citar}

CASTRELlón PÉrez, M. y Romero Cristancho, C. (2016). Enfoque de género en la implementación de la Ley de Víctimas y Restitución de Tierras: una propuesta para la caracterización de las mujeres y niñas víctimas del conflicto armado en Colombia. Revista CS, no. 19, pp 69-113. Cali, Colombia: Facultad de Derecho y Ciencias Sociales, Universidad Icesi.

DOI: http://dx.doi.org/10.18046/recs.i19.2166 
El objetivo de este artículo es hacer una propuesta metodológica para incorporar la perspectiva de género en las herramientas de planeación de la Ley de Víctimas y Restitución de Tierras a nivel territorial. Las medidas de reparación integral a favor de las mujeres deben reconocer que las violencias producto del conflicto superan el episodio mismo y agudizan las brechas de inequidad y goce efectivo de derechos entre hombres y mujeres. Por lo tanto, todo intento de caracterización de las mujeres sobrevivientes del conflicto debe tener en cuenta: la situación de las mujeres en los diferentes ámbitos de exclusión como el acceso a la vivienda y tierra, el nivel de educación, la autonomía económica, y los diferentes tipos de discriminación que viven en tiempos de paz, como puntos de partida para la formulación de políticas de prevención y reparación integral de las mujeres en los territorios.

\section{PALABRAS CLAVE:}

Género | Entidades territoriales | Ley de Víctimas y Restitución de Tierras |

Caracterización | Planes de Acción Territorial | Conflicto armado

The purpose of this article is to present a methodological proposal to be included by local governments in their planning tools to implement the Victims and Land Restitution Law. Integral reparation measures on behalf of women who have been victimized by the armed actors have to recognize that the victimization oversees the violent episode and exacerbates inequality gaps and the effective enjoyment of rights between men and women. Hence, any attempt to characterize women survivors of the conflict must consider women's situation in different areas of exclusion such as access to land and housing, educational level, economic independence, among others; as well as the different types of discrimination that women face during peace times. All this to formulate public policy that aims at preventing violence and repairing women in local territories.

\section{KEY WORDS:}

Gender | Local governments | Victims and Land Restitution Law | Characterization | Local Action Plans $\mid$ Armed conflict 
O objetivo deste artigo é fazer uma proposta metodológica para incorporar a perspectiva de gênero nas ferramentas de planejamento da Lei de Vítimas e Restituição de Terras a nível territorial. As medidas de reparação integral a favor das mulheres devem reconhecer que as violências produzidas pelo conflito superam o próprio episódio e agudizam as brechas de iniquidade e gozo efetivo de direitos entre homens e mulheres. Por tanto, toda tentativa de caracterização das mulheres sobreviventes do conflito deve levar em conta: a situação das mulheres nos diferentes âmbitos de exclusão como o acesso à moradia e terra; o nível de educação; a autonomia econômica, entre outras; e os diferentes tipos de discriminação que vivem em tempos de paz, como pontos de partida para a formulação de políticas de prevenção e reparação integral das mulheres nos territórios.

\section{PALAVRAS CHAVES:}

Gênero | Entidades territoriais | Lei de Vítimas e Restituição de Terras | Caracterização | Planos de Ação Territorial | Conflito armado 


\section{Introducción}

La institucionalidad colombiana se ha volcado desde la expedición de la Ley 387 de 1997, bajo el gobierno de Ernesto Samper Pizano, a idear y poner en marcha diferentes sistemas de protección, atención y reparación a la población víctima del conflicto y desplazamiento forzado en Colombia. Posteriormente, con el gobierno Uribe Vélez en el marco de la Ley 975 de 2005, se instaló un programa de reparación individual por vía administrativa de las víctimas de los procesos de Justicia y Paz. Para llegar al actual Sistema Nacional de Atención y Reparación a las Víctimas (SNARIV) como resultado de la expedición de la Ley de Víctimas y Restitución de Tierras (Ley 1448 de 2011) en el primer gobierno de Santos Calderón.

En ese sentido y bajo la trayectoria recorrida por la institucionalidad para atender a la población víctima resulta pertinente, ad portas de la firma del Acuerdo de la Habana con las FARC-EP, preguntarse por los aprendizajes obtenidos en la materia, bajo la premisa que la reparación es una de las vías para el logro de una paz estable y duradera. Bajo esa misma lógica y atendiendo los objetivos del presente artículo quisiéramos dar respuesta al siguiente interrogante: ¿Qué hemos aprendido en materia de reparaciones para las mujeres?

Esta pregunta enmarca el propósito general de este artículo, toda vez que buscamos hacer una reflexión sobre el acercamiento de la institucionalidad a la reparación de mujeres y niñas que han sido víctimas del conflicto armado. Con esto pretendemos hacer un aporte muy concreto y proponer una mirada multidimensional a la hora de reparar a las mujeres que ingresaron a la ruta administrativa de la Ley de Víctimas y Restitución de Tierras. La cual, a nuestro modo de ver, se aleja de aquella que sitúa la violencia sexual como el daño central que han sufrido las mujeres a lo largo del conflicto.

Esto, sin embargo, no quiere decir que no reconozcamos la existencia del uso de la violencia sexual por parte de actores armados como un medio para dominar, controlar y atemorizar (Centro de Memoria Histórica), ni el hecho de que son las mujeres quienes desproporcionadamente han sufrido este tipo de victimización, tal y como lo ha reiterado la Corte Constitucional en sus autos de seguimiento de la sentencia T-025 de 2004 y los informes de las organizaciones nacionales e internacionales.

En la medida que el objetivo es llamar la atención sobre la necesidad de aproximarse a la reparación de las mujeres víctimas desde una perspectiva que incluya su situación social, económica y política, para acercarnos a una verdadera transformación de las estructuras sociales patriarcales. Una aproximación con enfoque de género no solo supone reconocer el efecto desproporcionado de la guerra en los cuerpos de las mujeres, evidente en la violencia sexual, sino porque las mujeres, cuando sufren otros daños, incluso los mismos que los hombres, tienen una experiencia particular marcada por su género (Rubio-Marin, 2006). 
Diferentes organismos nacionales e internacionales han alertado sobre los diversos y múltiples efectos del conflicto colombiano en los cuerpos, psiquis, vidas, derechos y familias de millones de mujeres ${ }^{1}$. El Centro de Memoria Histórica $(\mathrm{CMH})$ reportó que al 31 de marzo de 2013 - entre 1985 y 2012- se registraron un total de 2.420 .887 mujeres víctimas de desplazamiento forzado; 2.601 registros de desaparición forzada; 12.624 casos de homicidio; 592 de minas antipersonal; 1.697 de reclutamiento ilícito; 5.873 de secuestro, y 1.431 reportes de violencia sexual (CMH, 2013). De acuerdo con el último reporte del Registro Único de Víctimas al 1 de enero de 2016, el total de mujeres víctimas del conflicto armado asciende a 3.773.262 (Unidad de Atención y Reparación Integral a Víctimas -UARIV—, Registro Único de Víctimas, página web).

En ese sentido, instancias internacionales y nacionales de protección de derechos humanos han sido enfáticas en recomendar al Estado colombiano que implemente medidas para erradicar patrones socioculturales discriminatorios en razón del sexo. Asimismo, han sugerido que en el desarrollo de políticas públicas, que busquen mitigar los efectos desproporcionados del conflicto armado en las mujeres colombianas, se tomen en cuenta las diferencias y condiciones de vulnerabilidad de las mujeres víctimas (Comisión Interamericana de Derechos Humanos, 2006: Recom.3). La falta de acceso y goce efectivo de derechos por parte de las mujeres constituye un factor de riesgo a la violencia en el marco del conflicto, tal y como se señaló recientemente en el Auto oo9 de 2015 de la corporación constitucional.

$\mathrm{Al}$ respecto, la Corte Constitucional y la Comisión Interamericana de Derechos Humanos (CIDH) coinciden en reconocer que las mujeres: i) sufren un impacto agudizado de la guerra en su cotidianidad; ii) enfrentan riesgos y hechos particulares en sus cuerpos y derechos, y iii) asumen cargas desproporcionadas a la hora de acceder a los sistemas y rutas de asistencia, atención y reparación que ofrecen las instituciones del Estado (Corte Constitucional, 2008, 2013, 2015; CIDH, 2006 y 2009).

Bajo esta mirada tridimensional de la discriminación de género en el conflicto, el objetivo de este artículo es generar una propuesta metodológica para dar contenido material al enfoque de género en el proceso de caracterización de las víctimas, y servir como insumo principal para las diversas herramientas de planeación de la Ley de Víctimas (Ley 1448 de 2011). Esta propuesta es necesaria y pertinente, toda vez que pareciera que las herramientas de planeación y caracterización para reparar a las víctimas

1. Respecto a las afectaciones concretas que sufren niñas y mujeres en el conflicto colombiano ver, entre otros: Mesa de Trabajo Mujer y Conflicto Armado, Informe sobre violencia sociopolitica en contra mujeres, jóvenes y niñas en Colombia 2000-2010, Bogotá; Olga Sánchez, Las violencias contra las mujeres en una sociedad en guerra, 2008; Naciones Unidas, Informe presentado por la Sra. Radhika Coomaraswamy, Relatora Especial sobre la violencia contra la mujer, sus causas y consecuencias: Misión a Colombia (1-7 de noviembre de 2001) E/CN.4/2002/83/Add.3, 11 de marzo de 2002; Amnistía Internacional, Colombia, Cuerpos Marcados, Crímenes silenciados: Violencia sexual contra las Mujeres en el Marco del Conflicto Armado, AMR 23/O4O/2004; Fondo de Desarrollo de las Naciones Unidas para la Mujer, Informe sobre la Situación de las Mujeres en Colombia, Septiembre de 2005. 
del conflicto desde un enfoque de género se limitan a dos variables: i) la identificación de episodios de violencia sexual de las víctimas; y ii) el reconocimiento de las mujeres como cabezas de familia que ingresan a la ruta de reparación. Este artículo tiene el objetivo de ampliar las variables del proceso de caracterización que tienen a cargo las administraciones locales a la hora de elaborar los Planes de Acción Territorial (PATS)². Teniendo en cuenta que dichos planes constituyen la hoja de ruta de los territorios para la implementación de los programas de prevención, asistencia, atención, protección y reparación integral a las víctimas (Art. 254, Ley 1448/11).

En consecuencia, el artículo propone una mirada que sobrepasa la mera caracterización de víctimas de acuerdo con los hechos victimizantes sufridos, para intentar responder a las complejas estructuras de discriminación que sitúan a las mujeres en una condición de desigualdad previa, durante y posterior al hecho sufrido. De esta manera, esperamos acercarnos a una aproximación metodológica a los principios sobre enfoque diferencial y reparación integral contenidos en la Ley.

Para ello, en la primera sección intentamos responder esta pregunta: ¿qué significa una mirada multidimensional de las diferentes manifestaciones del género de las violencias en el conflicto armado? En la segunda sección, proponemos seis variables que dan cuenta del nivel de goce efectivo de derechos y acceso a servicios de las mujeres en los territorios, con el fin de ser incorporadas o validadas en los procesos de caracterización para la elaboración de los Planes de Acción Territorial o Planes de Desarrollo, en su defecto. Para concluir con algunas reflexiones sobre los retos de la propuesta de caracterización.

\section{Una mirada multidimensional a las manifestaciones del género en el marco del conflicto armado en Colombia: más allá de la violencia sexual}

La centralidad de la violencia sexual como daño principal de las mujeres en los conflictos alrededor del mundo surgió a principios de los años 90 durante los juicios internacionales contra la antigua Yugoslavia. Las masivas violaciones a mujeres, y la falta de reconocimiento como un crimen de guerra, generaron una fuerte reacción por parte

\footnotetext{
2. Los Planes de Acción Territorial son la herramienta principal de planeación para los departamentos y municipios. Estos contemplan medidas de prevención, atención, asistencia y reparación integral a las víctimas del conflicto armado. Los PATS contienen programas y proyectos municipales y departamentales en torno a: asistencia y atención, reparación integral, prevención y protección, verdad y justicia, a través de ejes transversales como enfoque diferencial, articulación interinstitucional, participación, retornos y reubicaciones. De esta manera, son el principal instrumento para la implementación de programas, acciones y estrategias definidas en los diferentes niveles de gobierno. Los Comités Territoriales de Justicia Transicional cumplen un importante rol en la aprobación y supervisión de la implementación de estos planes.
} 
de activistas feministas que llevó al reconocimiento de la violencia sexual como un crimen de lesa humanidad en los estatutos de los tribunales ad hoc para juzgar los delitos cometidos en la antigua Yugoslavia y Ruanda (Mendia Azkue, 2012). Más adelante, en 1998, la violencia sexual fue reconocida como crimen de lesa humanidad en el Estatuto de Roma, dándole así una prevalencia que ha copado prácticamente por completo el entendimiento de otros tipos de daños que sufren las mujeres en los conflictos armados.

De acuerdo con Helena Alviar e Isabel Cristina Jaramillo (2012), en el caso colombiano la prevalencia de la violencia sexual como daño principal sufrido por las mujeres, se deriva no solo por la fuerza que tomó esta victimización a partir de su reconocimiento en el Estatuto de Roma, sino también porque se ha encontrado que en otros hechos victimizantes - entre otros: homicidios y desapariciones, desplazamiento forzado, reclutamiento de menores y despojo de tierras - los hombres han sido víctimas directas con más frecuencia que las mujeres. Esto ha generado que se entienda que aquello que compete a las mujeres es lo relacionado con la violencia sexual.

Esta situación también es puesta en evidencia por parte de las autoras Julieta Lemaitre y Kristin Bergtora, quienes con evidencia empírica hacen un llamado a descentralizar la violencia sexual del debate sobre la reparación a las mujeres víctimas. Tras un largo y profundo trabajo de campo con organizaciones de mujeres víctimas de desplazamiento forzado en Colombia, las autoras señalan que los daños que han sufrido las mujeres se deben observar y entender bajo una lupa que no incluya de manera exclusiva o principal la violencia sexual. Por ejemplo, en el estudio de caso realizado por las autoras, encontraron que la inseguridad política es un daño que tiene un impacto de género en las mujeres (esto quiere decir que impacta a las mujeres de forma diferenciada por tratarse de mujeres) pues no les permite ejercer por completo su ciudadanía (Lemaitre y Bergtora, 2014).

Asimismo, Alviar y Jaramillo señalan los riesgos que se corren cuando la violencia sexual se presenta como el daño principal que sufren las mujeres en el marco del conflicto armado. En palabras de las autoras podemos identificar tres riesgos que surgen a partir de la centralidad de la violencia sexual como categoría.

El primero es "exotizar" la violencia sexual como daño de las mujeres, dejando de lado que algunas sufren perjuicios económicos y menoscabo a su ciudadanía política que no son consecuencia de la mencionada violencia [...]. El segundo es exotizar la guerra como situación de excepcionalidad en la que las mujeres sufren daños que no son parte de su cotidianidad o que no sufren quienes no están en guerra. El tercero es excluir a la mujeres de la posibilidad de negociar transformaciones más completas de su cotidianidad al insistir en que los daños padecidos se reducen a los ocasionados por la guerra y reducir los daños de la guerra a la violencia sexual (Alviar y Jaramillo, 2012). 
Así, es importante reconocer que las circunstancias tradicionales de exclusión que han sufrido las mujeres en sus esferas afectivas, sociales, políticas, económicas, entre otras, han sido manipuladas y explotadas por los actores del conflicto (CIDH, 2006). En esa medida, las discriminaciones estructurales que afectan la vida diaria de las mujeres se agudizan en tiempos de guerra, generando efectos perversos y desproporcionados sobre sus derechos.

La CIDH ha comprobado que los efectos de la guerra son distintos para hombres y mujeres. La fuente de esta diferencia radica en que

Las mujeres han sufrido situaciones de discriminación y violencia por el hecho de ser mujeres desde su nacimiento y el conflicto armado se suma a esta historia ya vivida. Para las mujeres, el conflicto armado es un elemento que agrava y perpetúa esta historia. La violencia y discriminación contra las mujeres no surge sólo del conflicto armado; es un elemento fijo en la vida de las mujeres durante tiempos de paz que empeora y degenera durante el enfrentamiento interno (CIDH, 2006: 16).

Durante el conflicto, la mayoría de las mujeres ven afectadas su cotidianidad y privacidad (CIDH, 2006) y deben sobreponerse tanto a los daños individuales como familiares y lograr inmediatamente la supervivencia, seguridad física y alimentaria de su núcleo familiar a cargo (ONU Mujeres, 2011). Para ello, deben enfrentar exitosamente las discriminaciones preexistentes en el ámbito laboral, económico, social y familiar. Según los relatos de mujeres víctimas contenidos en el informe !Basta ya: Colombia: memorias de guerray dignidad!, la violencia política se sumó de manera desproporcionada a la situación de inferioridad, control y dominación privada como social que reproduce una sociedad patriarcal en la vida de las mujeres, para desestructurar sus familias, y desterrarlas de los espacios ( $\mathrm{CMH}, 2 \mathrm{O13})$.

En el caso concreto de Colombia, la Corte Constitucional ha reconocido que los efectos en el contexto de la guerra continúan siendo especialmente desproporcionados para las mujeres, ya que en muchas ocasiones deben enfrentarse a la pérdida del proveedor económico, asumir el rol de madres cabeza de familia y cargar con las afectaciones psicológicas, económicas y físicas que originaron el hecho victimizante (Corte Constitucional, 2008). En términos del $\mathrm{CMH}$, las mujeres víctimas del conflicto han tendido que asumir los procesos legales, los trámites administrativos y en ocasiones las demandas de justicia, sin estar preparadas para ello. Lo que ha representado jornadas extenuantes; someter a sus hijos al encierro o a largas horas de abandono, al maltrato por los actores del conflicto y agentes del Estado, y la represión de sus sentimientos, entre otras afectaciones a sus vidas y derechos más esenciales (CMH, 2013). 
De acuerdo a este reconocimiento sobre los efectos desproporcionados de las mujeres en la guerra, el presente artículo define tres niveles de discriminación que permitirán comprender las diferentes dimensiones de la discriminación de género en el conflicto armado, con el fin de generar herramientas de gestión e información para una caracterización integral de las mujeres víctimas del conflicto.

El primer nivel de discriminación obedece al reconocimiento de las situaciones estructurales y tradicionales de exclusión de la población femenina en el contexto colombiano, con relación a los tratamientos desiguales que reciben a la hora de acceder a servicios de primer orden, y los diferentes tipos de violencia que viven en tiempos de paz (CIDH, 2006). Sobre este punto, La Corte Constitucional en Auto reciente evidencia que gracias a los entornos de desigualdad estructural de las mujeres en los territorios, evidente en la precariedad socioeconómica de estas y la debilidad de la institucionalidad para garantizarles el goce efectivo de sus derechos, se generan los factores de riesgo para que las mujeres sean víctimas de los delitos de trata de personas, tráfico de drogas, reclutamiento, entre otras actividades ilegalidades de la ruta de la guerra (Corte, 2015).

En un segundo nivel de discriminación relacionado con el rol social del cuerpo de las mujeres (Corte Constitucional, 2008; CIDH, 2006 y 2009). La Corte ha resaltado que la guerra tiene modalidades de acción específica sobre el cuerpo y la vida sexual y reproductiva de las víctimas al enfatizar que la violencia sexual, la explotación sexual, la esclavitud y reclutamiento forzado para ejercer labores domésticas, la prostitución forzada, el requerimiento y la coerción para ejercer comportamientos específicos en el ámbito privado y público, entre otros, son hechos sufridos mayoritariamente por las niñas y mujeres colombianas (Corte Constitucional, 2008). Asimismo, la Comisión ha señalado que la violencia física, psicológica y sexual, el desplazamiento forzado, el reclutamiento forzado y la imposición de modelos de comportamiento caracterizan las principales situaciones de discriminación de las mujeres en el marco del conflicto armado colombiano (CIDH, 2006).

Las prácticas anteriormente mencionadas contra las mujeres han sido reconocidas como constantes, habituales y sistemáticas (Corte Constitucional, 2008) y han dejado de ser concebidas como experiencias aisladas de la vida privada de las víctimas (ONU Mujeres, 2011). Según la Comisión, la violencia sexual, física y psicológica cometida contra niñas y mujeres ocurre en el curso de:

i) ataques, masacres y homicidios perpetrados contra comunidades y sus habitantes en su lucha por controlar recursos y territorio; ii) homicidios, actos de tortura, y señalamientos contra las mujeres por tener relaciones afectivas con simpatizantes o combatientes o por estar involucradas directamente o a través de sus familiares en actividades políticas; y (iii) de detenciones, registros domiciliarios y secuestros para obtener información, aterrorizarlas, castigarlas, intimidarlas o coaccionarlas (CIDH, 2006: párr. 55). 
Por lo tanto, se podría afirmar que un gran número de las agresiones cometidas contra la integridad y libertad sexual de las mujeres constituyen la antesala de masacres, secuestros, desapariciones y registros domiciliarios; y en ese sentido muchas veces los delitos de carácter sexual no son registrados como tales y quedan diluidos en otros hechos victimizantes de carácter público.

El tercer nivel de discriminación de las mujeres en el conflicto podemos relacionarlo con la permanencia de las dificultades que las mujeres resisten a la hora de acceder a las rutas de atención y reparación administrativas y judiciales que ofrece el Estado. Desde el 2008, la Corte alertó sobre seis tipos de obstáculos que soportan las mujeres frente al sistema de atención a la población desplazada como manifestaciones específicas de la discriminación, tales como: i) requerimientos especiales de atención y acompañamiento psicosocial; ii) la persistencia de un enfoque "familista" que descuida a un altísimo número de jóvenes y mujeres que no son cabeza de familia en la ruta de atención y reparación; iii) la falta de comprensión de los agentes del SNARIV sobre enfoque de género; entre otros (Corte Constitucional, 2008: 94).

En el mismo sentido, la CIDH ha identificado ciertos desafíos de la inclusión de la perspectiva de género en la implementación de las políticas de justicia transicional. Por ejemplo, ha señalado su preocupación por la falta de recursos, formación institucional y diligencia debida para registrar información cualitativa y cuantitativa sobre los casos de violencia de género y violencia sexual que soportan las mujeres afectadas por las dinámicas del conflicto. Adicionalmente, ha identificado los peligros de realizar un enfoque diferencial que perpetúe una visión de mujer como un grupo homogéneo de la sociedad sin discriminaciones y afectaciones interseccionales. Por esto, se ha recomendado e instado al gobierno colombiano a diseñar y aplicar "políticas diferenciales" de prevención y reparación que incluyan las diversas necesidades de ciertos grupos de mujeres (CIDH, 2006 y 2009).

A manera de advertencia metodológica, el CONPES 3784 de 2013 define el enfoque de género como aquel que:

[...] se refiere al análisis de las relaciones sociales que parte del reconocimiento de las necesidades específicas de las mujeres y que tiene por objeto permitir la igualdad real y efectiva entre hombres y mujeres. Desde esta mirada se pretende desarrollar e impulsar acciones que propicien el ejercicio de la ciudadanía de las mujeres, que disminuya las brechas de género y, en el contexto del conflicto armado, la disminución del impacto diferencial y desproporcionado de género. Así entonces, el enfoque de género implica: i) el reconocimiento de las relaciones de poder que se dan entre los géneros, en particular consideración de los masculino y sus significantes como superiores, derivando en relaciones de poder injustas y desiguales; y ii) el abordaje de las relaciones de género que se han constituido social e históricamente y atraviesa todo el entramado social articulándose con otras relaciones sociales, como la etnia, edad, identidad sexual y condición social y económica. 


\section{Variables para la caracterización de las mujeres víctimas: una respuesta a la mirada multidimensional}

A partir de las tres dimensiones de la discriminación de género en el conflicto armado, proponemos una serie de variables a tener en cuenta en los procesos de caracterización en los territorios que permita recoger información sobre el primer y segundo nivel de desigualdad que sufren las mujeres en el conflicto. Esto con el objetivo de hacer una caracterización que dé cuenta del contexto situacional en el que se encuentran las mujeres.

Ahora bien, hacer un contexto situacional implica hacer un ejercicio inicial de identificar qué se quiere observar y por qué es importante hacerlo. De acuerdo con los lineamientos de la Política Pública Nacional de Equidad de Género para las Mujeres, la desigualdad estructural de género se reconoce al establecer que "algunos indicadores muestran todavía la persistencia de graves discriminaciones que influyen negativamente sobre el desarrollo pleno de las mujeres y que se reflejan, entre otras, en altos índices de violencia basada en género, serias desigualdades en el mercado laboral y baja participación en los cargos de poder y toma de decisiones"(Alta Consejería Presidencial para la Equidad de la Mujer, 2012). En la misma línea, el CONPES 3784 de 2013, mencionado previamente, resalta que la

\footnotetext{
Oferta institucional debe avanzar en la comprensión de las afectaciones particulares y las necesidades diferenciadas que tienen las mujeres víctimas en el marco del conflicto y para lo cual se hace necesario: i) generar estadísticas que tengan en cuenta variables que atiendan las diferentes condiciones y situaciones que enfrentan las mujeres como ciudadanas, y no sólo en relación al núcleo familiar; y ii) flexibilizar la oferta institucional para la atención de las condiciones relacionadas con el ciclo vital, identidad de género, pertenencia étnica, orientación sexual, discapacidad, entre otras de las mujeres víctimas.
}

En este sentido, es importante que en la caracterización de las mujeres se analicen variables que superen el registro de los hechos victimizantes que sufren en el conflicto, porque las mujeres en general y especialmente aquellas víctimas del conflicto, ven obstaculizados sus derechos debido a las condiciones estructurales de desigualdad. Adicionalmente, para el caso de estas últimas la situación se agudiza debido a que la victimización genera mayores vulnerabilidades, y por esto es necesario diseñar estrategias que apunten a transformar estas condiciones y a reparar a las mujeres y niñas víctimas desde una perspectiva de género que comprenda las diferencias de esta población.

Las variables que posibilitan el registro más allá de los hechos victimizantes y que deberían ser incorporadas en la caracterización de las mujeres y niñas, se plantean a partir de la propuesta de la Política Pública Nacional de Equidad de Género para la Mujer. Esta política identifica las temáticas que "afectan el goce de los derechos de las mujeres en Colombia y que impiden u obstaculizan su capacidad para generar 
autonomía, así como su plena participación en la toma de decisiones sobre su vida y la de su colectividad" (Alta Consejería Presidencial para la Equidad, Lineamientos de la Política Pública Nacional de Equidad de Género para las Mujeres, 2012: 16). Estas variables permitirán construir un mapa completo sobre la situación de las mujeres en las entidades territoriales.

Las variables a construir o ubicar en los diferentes sistemas de información son:

1. Autonomía económica, dentro de la cual se incluyen: (a) la Jefatura Femenina, (b) Igualdad laboral y (c) Informalidad laboral y desempleo.

2. Acceso a vivienda y a tierras.

3. Participación política.

4. Salud integral en las esferas de (a) Afiliación al sistema de salud, (b) Conocimiento y acceso a métodos de planificación, (c) Embarazo adolescente, (d) Interrupción voluntaria del embarazo, (e) VIH, (f). Mortalidad materna y (g) Salud mental.

5. Educación en cuanto a (a) La tasa de analfabetismo, (b) Acceso y nivel.

6. Tipos de violencias contra las mujeres.

\section{Autonomía económica}

La CIDH ha alertado que la discriminación contra las mujeres se sigue reflejando en el mercado de trabajo y su acceso limitado a la seguridad social. Para este organismo, la garantía de la autonomía económica es un componente clave para erradicar la pobreza y la marginalización, con repercusiones concretas en el ejercicio de otros derechos esenciales de las mujeres (CIDH, 2011). Es importante reconocer que históricamente las labores del hogar o trabajo reproductivo han estado a cargo de las mujeres y no han recibido ningún tipo de remuneración por estas (Peña et. al., 2013). Esto, además de otros factores, ha generado una desigualdad en la capacidad económica entre hombres y mujeres, y como tal ha afectado la autonomía de estas últimas para tener acceso a créditos, cotización en pensiones y ahorros.

Algunos de los elementos que permiten evidenciar la autonomía económica de la mujer son:

- La capacidad de generar ingresos y decidir sobre su uso.

- La posibilidad de participar en las decisiones referentes al ingreso generado por cada uno de los miembros del hogar.

- La capacidad de adquirir activos (o bienes) a nombre propio, así como utilizar y disponer de estos según criterios propios. 
- La posibilidad de participar en las decisiones del hogar referentes a la adquisición de activos, a cómo se van a utilizar y disponer dichos activos (Deere, 2011).

\section{(a) Jefatura Femenina}

Se entiende que hay jefatura femenina en dos circunstancias: (i) cuando la mujer es la única proveedora del hogar, bien sea porque es soltera, viuda o separada; o (ii) cuando la mujer es quien trae los ingresos económicos al hogar, a pesar de existir una figura masculina dentro del mismo. La jefatura femenina no debe ser entendida como un problema u obstáculo per se para la autonomía económica de las mujeres jefes de hogar. Actualmente en Colombia el 32\% de los hogares tienen jefatura femenina (Alta Consejería, 2012). Sin embargo, las cifras a nivel nacional que arroja la Gran Encuesta Integrada de Hogares de 2011, indican que en la mayoría de los casos en los que una mujer es jefe de hogar, esta es viuda, separada o soltera (76\%), mientras que los hombres jefes de hogar en su mayoría son casados o viven en unión libre (83\%). Esto sí genera una diferencia en la capacidad económica entre hombres y mujeres, pues esta se disminuye cuando no hay un segundo adulto responsable del trabajo reproductivo y es la mujer quien debe asumir todas las cargas.

\section{(b) Igualdad laboral}

La concepción social de las relaciones familiares - formado bajo un modelo discriminatorio - que asigna mayoritariamente la responsabilidad del cuidado de la familia a las mujeres, limitando sus oportunidades para incursionar en el mercado laboral, ha determinado una falta de igualdad y de distribución del trabajo remunerado y no remunerado entre la mujer y el hombre (CEPAL, 2007: 5)).

Así mismo, la división sexual del trabajo es uno de los núcleos de mayor desigualdad entre los sexos, en razón de las estructuras rígidas de la división de tareas, reguladas por normas sociales asociadas al carácter reproductivo de las mujeres versus el carácter proveedor del hombre (CEPAL, 2007:55; Peña et. al, 2013; Savogal, 2012). La desigualdad laboral entre hombres y mujeres se puede manifestar en distintas esferas; entre estas se identifica: el acceso desigual al mercado laboral; la desigualdad en la remuneración; y los altos niveles de informalidad que afectan a las mujeres. Mientras que el $69 \%$ de los hombres en edad de trabajar lo hacen, solo el 45,2\% de las mujeres en esta misma edad tiene un trabajo. Vale la pena destacar que el $27,8 \%$ de las mujeres en edades productivas se dedica al trabajo reproductivo. (Alta Consejería, 2012). 


\section{(c) Informalidad laboraly desempleo}

La informalidad laboral afecta a mujeres y a hombres en la medida en que su ocupación no les garantiza estabilidad, acceso al sistema de seguridad social y prestaciones laborales. Según ONU Mujeres (2011), a nivel mundial el 53\% de las mujeres que trabajan lo hacen en espacios de alta vulnerabilidad, a menudo por cuenta propia o sin percibir un salario, en empresas familiares o relacionadas con el sector rural. En Colombia, la tasa de informalidad para las mujeres es de 67,9\% y la de los hombres es de $63,5 \%$ (Alta Consejería, 2012).

\section{Acceso a vivienda y tierras}

$\mathrm{El}$ acceso y control sobre la tierra es la base de los medios de sustento de las mujeres en los territorios. En muchos países la falta de acceso de las mujeres a la tierra y sus recursos está ligada a factores de discriminación histórica en temas de divorcio y sucesión (ONU Mujeres, 2011), como reglas culturales de ciertas comunidades, donde generalmente son los hombres los agentes legítimos para ejercer el derecho de propiedad. El Gobierno Nacional reconoce las dificultades para acceder a datos oficiales que permitan conocer la relación formal de las mujeres frente a la propiedad y las "afectaciones particulares que han sufrido las mujeres por el despojo o abandono de sus tierras en el marco del conflicto" (CONPES, 2013). A partir de aproximaciones de cifras oficiales sobre acceso a tierra y a vivienda se puede deducir que el acceso de las mujeres a este tipo de bienes es limitado, en gran parte porque usualmente estas no figuran en los trámites contractuales. Así lo demuestran las cifras del anterior Incoder sobre participación de mujeres en la titularidad de la tierra, en casos de población en riesgo y desplazamiento: "el 65\% de los derechos sobre las tierras protegidas entre 2003 y julio de 2010 corresponde a hombres, frente a un $33 \%$ que atañe a mujeres. De estas, el $26,1 \%$ son propietarias, el $42,4 \%$ poseedoras, el $18 \%$ ocupantes y el 9,4\% tenedoras" (Alta Consejería 2012: 39). Así mismo, esta tendencia también se refleja en las cifras actuales de la Unidad de Restitución de Tierras en las que de 32.688 solicitudes tan solo 12.152 corresponden a solicitudes de mujeres, mientras que 20.424 corresponden a solicitudes de hombres (Unidad de Restitución de Tierras, 2013).

\section{Participación política y espacios de poder}

La participación política de mujeres significa que estas tengan el espacio propicio para hacer una intervención ciudadana como actoras sociales o políticas para expresar sus intereses, expectativas y demandas en la esfera pública (Alta Consejería, 2012). Para ONU Mujeres, la formulación e implementación de reformas legales encaminadas a 
ampliar los derechos de las mujeres y sus niveles de acceso a la justicia están a menudo relacionados con aumentos significativos en la representación de las mujeres en instancias legislativas y decisorias (ONU Mujeres, 2011).

El ejercicio político puede verse reflejado en distintos cargos y niveles. Este ejercicio va desde los cargos nacionales o de elección popular, que tienen mucha visibilidad, hasta cargos que se ejercen a nivel local, incluso entre una comunidad. La importancia de garantizar el ejercicio y la participación política de las mujeres en la esfera pública/ política radica en que es el escenario por excelencia donde se toman las decisiones que las pueden afectar o beneficiar. No obstante, se ha reconocido la exclusión histórica de las mujeres en los espacios públicos en razón, entre otros determinantes, de la ocupación de la población femenina en "las labores del hogar, cuidado de sus hijos/as y escaso nivel educativo que unido a prácticas patriarcales no permiten que las mujeres exploren sus capacidades políticas, ni ejerzan labores de liderazgo". Así mismo por la ausencia de garantías para la participación y protección de la mujeres líderes, deslegitimación de su rol como líderes en sus comunidades, entre otros factores identificados en el CONPES 3784 de 2013 .

\section{Salud integral}

Las mujeres que han sido históricamente marginadas por motivos de raza, etnia o posición económica, son quienes menos acceso a servicios de salud poseen a nivel mundial (CIDH, 2010). Según la Cuarta Conferencia Internacional sobre la Mujer de la ONU, el principal obstáculo que impide a la mujer alcanzar el más alto nivel posible de salud es la desigualdad entre hombres y mujeres y entre las mismas mujeres en zonas rurales, clases sociales y grupos indígenas y étnicos (Naciones Unidas, 1995).

Es importante reconocer que niñas y mujeres requieren información y atención a servicios de salud diferenciada, en razón de las particularidades biológicas, sexuales y reproductivas que ellas tienen frente a los hombres. Abordar y conocer los diferentes aspectos relacionados con el acceso a la salud de las mujeres permite conocer, de un lado, el nivel de desarrollo y calidad de vida de las mujeres, y por el otro, el nivel de respeto de los derechos a la integridad personal, autonomía y vida privada de las mujeres en las esferas más íntimas de su existencia.

Asimismo, es importante tener información sobre la tasa de afiliación al sistema de salud SGSSS; sobre tasas de VIH/Sida, acceso a aborto legal, y salud mental de las mujeres. Estos son criterios importantes a valorar a la hora de conocer el estado de salud de las mujeres en los territorios. 


\section{(a) Embarazo adolescente}

De acuerdo con el CONPES 147 de 2012 es necesario que las entidades públicas competentes pongan su atención sobre la problemática del embarazo adolescente, pues tiene fuertes implicaciones en el desarrollo y en la calidad de vida de los y las adolescentes y sus familias.

La ocurrencia de embarazos adolescentes a temprana edad ha sido considerada una problemática social y de salud pública necesaria de ser intervenida a fin de procurar un mejor desarrollo individual, una mejor calidad de vida y mejores índices de desarrollo. Además de presentar riesgos en el plano biológico, el embarazo en la adolescencia trae consigo eventuales riesgos que ponen en desequilibrio el bienestar integral y las expectativas de vida; ocasionan eventuales deserciones o discriminaciones en los contextos educativos y sociales; vinculación temprana al mercado laboral; mayores probabilidades de ingresar a cadenas productivas de subempleo u otras formas inestables de relación laboral (CONPES, 2012:4).

\section{(b) Mortalidad materna}

Según la Organización Mundial de la Salud (OMS), la mortalidad materna es un indicador de la disparidad y desigualdad entre los hombres y las mujeres, y su incremento es un signo de la ubicación de la mujer en la sociedad y su acceso a servicios sociales, de salud, nutrición y a oportunidades económicas (OMS, 1999). Es importante advertir que en el caso de los hombres, no hay una causa única de muerte y discapacidad cuya magnitud se aproxime a la incidencia de mortalidad y morbilidad materna (Relator Especial sobre el derecho a la salud, 2006). El indicador de mortalidad materna muestra el volumen de las muertes de mujeres asociadas al embarazo. Usualmente las mujeres que se ven más afectadas por la mortalidad materna son mujeres que pertenecen a poblaciones indígenas, mujeres pobres o adolescentes que no planificaron su embarazo (Alta Consejería, 2012).

\section{Educación}

Educar a las niñas y mujeres evita la transmisión de la pobreza entre generaciones y fomenta el progreso de una sociedad. Las mujeres con mayor nivel de educación tienen menos descendencia y sus hijos tienen más probabilidades de asistir a la escuela. En casi todas las regiones del mundo, las mujeres tienen más probabilidades que los hombres jóvenes de tener cuatro años menos de educación primaria (ONU Mujeres, 2011: 106).

De acuerdo con las cifras nacionales actuales, Colombia ha avanzado en la paridad entre hombres y mujeres en la cobertura en educación (Alta Consejería, 2012). A pesar de esto, es necesario comprender que la igualdad de género en la educación supone 
mucho más que dicha paridad. Ésta implica que a niñas y niños se les otorguen las mismas oportunidades de ir a la escuela, que los planes educativos no incluyan contenidos que puedan reforzar los estereotipos contra la mujer o con intenciones sexistas y que obtengan los mismos conocimientos, títulos y oportunidades de ingresar al mercado laboral. (Alta Consejería, 2012). Las variables a tener en cuenta para conocer el nivel educativo de las mujeres y niñas son: tasa de analfabetismo y acceso y nivel educativo.

\section{Violencia contra las mujeres}

La violencia ejercida contra mujeres y niñas es la manifestación extrema de la desigualdad y la discriminación por motivos de género, y en determinadas ocasiones constituye un arma mortal para lograr la subordinación física, sexual y psicológica de la población femenina (ONU Mujeres, 2011). Para los tratados internacionales, la violencia contra las mujeres y su raíz, la discriminación, es un problema grave de derechos humanos, con repercusiones negativas para toda la comunidad. Adicionalmente, constituye un impedimento para el goce efectivo de los derechos a la vida, integridad física, psíquica y sexual de las mujeres.

\section{(a) Violencia Intrafamiliar}

Este tipo de violencia es el que más afecta a las mujeres. De acuerdo con las estadísticas de Medicina Legal, de 261.581 casos de maltrato de pareja que se presentaron en los años 2007-2011, el 88\% corresponde a mujeres. Adicionalmente, de las 1.415 mujeres que fueron asesinadas en el año 2011, 9,6\% fueron asesinadas por su pareja o ex pareja (Medicina Legal, 2011). Pese a las dificultades del registro que presentan los casos de violencia intrafamiliar, en Colombia la tasa de este tipo de violencia es relativamente alta: $196,53 \%$ por cada cien mil habitantes. Este tipo de violencia históricamente ha afectado más a las mujeres, quienes presentan una tasa total de $302 \%$ frente al $87 \%$ que presentan los hombres.

\section{(b) Violencia sexual}

La violencia sexual abarca otras conductas que van más allá de la violación sexual. Dentro de este tipo de violencia se encuentra:

El acoso sexual, incluida la humillación sexual, el matrimonio o cohabitación forzados, incluido el matrimonio de menores, la prostitución forzada y comercialización de mujeres, la esclavitud sexual, la desnudez forzada, el aborto forzado, el embarazo forzado, la este- 
rilización forzada, la denegación del derecho para el uso de la anticoncepción o a adoptar métodos anticonceptivos, la amenaza de violencia sexual, el chantaje sexual, los actos de violencia que afecten la integridad de las mujeres, tales como la mutilación genital femenina y las inspecciones para comprobar la virginidad (CNRR-Grupo de Memoria Histórica, 2011).

Asimismo, se puede incluir información sobre las tasas de incidencia de violencia psicológica, inasistencia alimentaria y trata de mujeres. Es importante reconocer que, la violencia psicológica se puede manifestar como expresión subyacente a todas las formas de violencia contra las mujeres, como el daño que causa en la psiquis la violencia física o sexual; o como un tipo de violencia autónoma, como los insultos, humillaciones, chantajes emocionales, amenazas, entre otros. Debe tenerse en cuenta la inasistencia alimentaria por su incidencia en la reducción de las capacidades de las mujeres de ser económicamente independientes, pues su fuente de ingreso se destina en su totalidad al cuidado de los hijos. En los casos en los que ni siquiera se cuenta con un ingreso, la inasistencia alimentaria se configura como una ruta expresa a la pobreza de las mujeres (Alta Consejería, 2012).

\section{(c) Hechos victimizantes y daños a las mujeres víctimas}

La Ley de Víctimas define en el artículo 3 que son víctimas aquellas personas que hayan sufrido un daño como consecuencia de infracciones al Derecho Internacional Humanitario o de violaciones graves y manifiestas a las normas Internacionales de Derechos Humanos con ocasión del conflicto armado. Si bien esta definición es lo suficientemente amplia para que los distintos tipos de daños ocasionados a las mujeres sean incluidos, la forma como se ha caracterizado a las víctimas y los registros existentes se limitan a los siguientes hechos victimizantes: homicidio, desaparición forzada, secuestro, lesiones que producen incapacidad permanente, lesiones que no producen incapacidad permanente, tortura o tratos crueles inhumanos y degradantes, delitos contra la libertad sexual, reclutamiento forzado y desplazamiento forzado (Decreto 4800 de 2011 y CONPES 3712 de 2011).

Esta clasificación, a pesar de basarse en la tipificación del Código Penal, limita en muchos sentidos la comprensión de la violencia que pueden sufrir las mujeres en el marco del conflicto armado y, a pesar de que los tipos de daños contra las mujeres podrían "encajar" en alguna de las categorías presentadas arriba, no permite registrar de manera clara y precisa estos daños. Por ejemplo: no es claro cómo se clasificaría un caso de servicio doméstico forzado: ¿podría ser un secuestro o un trato cruel?; si se trata de una menor ¿reclutamiento forzado? Esta idea se puede reforzar si revisamos los delitos que se incluyen dentro del Código Penal bajo el título de Delitos contra la libertad, integridad y formación sexuales. Dentro de estos se incluyen: (i) el acceso carnal violento; 
(ii) acto sexual violento3; (iii) el proxenetismo; (iv) el constreñimiento a la prostitución; y (v) la pornografía de menores.

Contrario a lo anterior, en el Estatuto de Roma se establecen algunas categorías que pueden describir y reconocer de forma mucho más precisa el tipo de daños que pueden sufrir las mujeres y que se podría tener en cuenta a la hora de hacer una caracterización de las mujeres víctimas ${ }^{4}$. En el Estatuto se incluyen como crímenes de lesa humanidad: (i) la violación; (ii) la esclavitud sexual; (iii) la prostitución forzada; (iv) el embarazo forzado; (v) la esterilización forzada o cualquier otra forma de violencia sexual de gravedad comparable (Estatuto de Roma). A pesar del reconocimiento amplio que hace el Estatuto de Roma sobre las conductas que pueden ocasionar perjuicio a las mujeres, persisten otros hechos que generan daños: el acoso sexual, incluida la humillación sexual, el matrimonio forzado y el comercio de mujeres, el aborto forzado, la denegación del derecho para el uso de la anticoncepción o a adoptar medidas contra enfermedades o la imposición del uso de métodos anticonceptivos, los actos de violencia sexual que afectan la integridad sexual como la mutilación genital femenina y las inspecciones para comprobar la virginidad. 5

La Corte Constitucional, con la expedición del Auto 092, contribuyó a una concepción más amplia al daño que sufren las mujeres a causa del conflicto armado. La Corte señaló que las mujeres pueden ser víctimas de:

[...] la violación colectiva o individual -a menudo seguida del asesinato de la víctima-, las torturas y mutilaciones sexuales, la prostitución forzada, la esclavización sexual, la desnudez pública forzada, la humillación sexual individual y colectiva, el sometimiento a violencia sexual como medio para obtener información, o la amenaza de violencia sexual, efectuados contra mujeres, jóvenes, niñas y adultas mayores, a menudo frente a sus familias o ante la totalidad de sus comunidades, así como su sometimiento a prácticas crueles, inhumanas y degradantes tales como bailes, desfiles, entretenimientos o acompañamientos forzados para complacer a los miembros de los grupos armados, y actos de sevicia cometidos públicamente contra sus cuerpos o cadáveres -tales como distintos desmembramientos o empalamientos, en varios casos de mujeres embarazadas y de mujeres vivas (Corte Constitucional, 2008).

El documento CONPES 3487 de 2013, señala que las mujeres victimizadas "enfrentan limitaciones para la garantía plan del goce efectivo de sus derechos con reconocimiento

3. El que realice en otra persona acto sexual diverso al acceso carnal mediante violencia. Artículo 206 del Código Penal.

4. Queremos hacer la salvedad de que este tipo de violencia también puede ejercerse contra los hombres y es necesario e importante reconocerlo. Sin embargo, hacemos énfasis en los daños contra las mujeres pues son quienes típicamente han sido victimizadas de esta forma.

5. Informe Mujeres y Guerra. Víctimas y resistentes en el Caribe Colombiano. Las conductas presentadas de violencia sexual se toman de la organización Estudios para la Defensa de los Derechos de las Mujeres. http://www.demus.org.pe 
de sus afectaciones particulares". Este documento se convierte en un avance para hacer visible las afectaciones diferenciadas del conflicto en la vida de las mujeres; compromete al gobierno nacional a generar una oferta específica para la atención de las problemáticas o factores de riesgos y vulnerabilidades particulares (DNP, 2013).

\section{Los Plantes de Acción Territorial como herramienta principal para la caracterización de las mujeres víctimas del conflicto armado}

Dentro de las medidas que se deben adoptar para el cumplimiento de la Ley 1448, el artículo 174 de la misma establece que las entidades territoriales deben diseñar, elaborar e implementar, a través de los planes de acción territorial (PATS), programas de prevención, asistencia, atención, protección y reparación a las víctimas, con el fin de responder a los distintos hechos victimizantes. En este sentido, los PATS deberán garantizar los derechos fundamentales de las víctimas desde una perspectiva diferencial, definir los recursos financieros, físicos, logísticos, humanos y técnicos necesarios, con el fin de asistir, atender y reparar de manera integral a las víctimas. Según la Unidad de Víctimas, el proceso de caracterización local para la elaboración de los plantes de acción territorial es la herramienta de gestión de la Ley de Víctimas en los territorios y constituye el momento preciso para identificar los aspectos necesarios para una adecuada formulación de acciones y estrategias encaminadas a lograr el goce efectivo de los derechos de la población víctima (UARIV, 2012). En consecuencia, proponemos que los procesos de caracterización para la elaboración de los PATS en los territorios reconozcan, por un lado, la situación de desventaja estructural en la que viven las mujeres en los territorios, y por el otro, los hechos de violencia que sufren en el conflicto en razón de su sexo y su rol social. De lo contrario, cualquier intento de implementación de la ley se quedará corto a la hora de ofrecer medidas con el propósito de que las mujeres superen los daños y desigualdades estructurales en la que viven en los territorios de manera real y efectiva.

Bajo esa perspectiva, resaltamos la importancia de que las herramientas de implementación, gestión y planificación territorial de la Ley de Víctimas reconozcan y partan de la identificación de la situación local de las mujeres en materia del goce efectivo de sus derechos, así como de los riesgos y hechos que sufren por el conflicto en razón de ser mujeres. Dicha recomendación, busca que las entidades territoriales logren crear una oferta integral diferenciada que apunte a satisfacer las necesidades y particularidades de la población femenina afectada por las dinámicas del conflicto.

En este sentido, una propuesta diferencial de género no puede agotarse en el reconocimiento sobreestimado de la violencia sexual como único hecho victimizante que 
afecta a las mujeres en el conflicto. Las herramientas de valoración y caracterización deben permitir a las autoridades identificar los daños que sufren las mujeres con una mirada que vaya más allá de la violencia contra la integridad sexual. Se requiere una mirada integral a la situación de las mujeres víctimas que supone un reconocimiento multidimensional y situacional del goce de los derechos de las mujeres en los territorios y la comprensión integral de las afectaciones agravadas que viven niñas y mujeres en las dinámicas del conflicto.

Proponer que la caracterización multidimensional se haga en los PATS, implica reconocer que serán las entidades territoriales las encargadas de llevar a cabo este ejercicio. Esto a su vez implica reconocer que hay una alta heterogeneidad en la capacidad financiera y humana en las entidades territoriales, y por lo tanto debe ponerse especial atención a brindar apoyo desde el nivel nacional a aquellos casos en los que las entidades territoriales no estén en capacidad de llevar a cabo su ejercicio de caracterización. Esto representa un gran reto, pues la Ley de Victimas no especifica cómo es que las entidades territoriales van a recibir un trato diferencial de acuerdo con sus capacidades (Castrellon, Taborda, Vargas, 2015).

No obstante, el enfoque diferencial de género debe ser incluido en las diferentes herramientas de caracterización, gestión, planeación, implementación y seguimiento de la Ley de Víctimas, con el propósito de construir diagnósticos y ofertas de servicios de atención, asistencia y reparación capaces de enfrentar y superar los índices de discriminación y violencia que viven mujeres y niñas en los territorios.

Una importante herramienta que puede facilitar la recolección de los datos necesarios para llevar a cabo una caracterización multidimensional es el PAARI (Plan de Atención, Asistencia y Reparación Integral), el cual se construye entre la víctima y funcionarios de la Unidad de Víctimas y tiene el objetivo de recoger la información necesaria para implementar las medidas de asistencia, atención y reparación integral a la cual tienen derecho las víctimas. Este plan tiene el objetivo de conocer si las víctimas cuentan con los componentes de subsistencia mínima (alojamiento, alimentación y salud) ${ }^{6}$ y recoger otra información relevante para el proceso de reparación.

Este trabajo propone una tabla (Anexo 1) que permitirá a los tomadores de decisión conocer el nivel en que los planes, en su diagnóstico, atendieron las seis variables contempladas previamente para dar cuenta de la situación situacional de las mujeres en los territorios; y saber además si se formularon programas tendientes a mejorar el nivel de goce efectivo de los derechos de las mujeres, a partir de proyectos de educación, salud, acceso a vivienda y tierras, acceso al trabajo, entre otros. También permitirá aproximarse a los diferentes daños que pueden sufrir las mujeres en el marco del conflicto armado. En este ejercicio es importante mencionar que los daños que se enlistan en la tabla son 
meramente enunciativos, por lo cual es posible que en los procesos de caracterización aparezcan otro tipo de daños.

Con el fin de asegurar diagnósticos integrales que tengan en cuenta que: (i) la discriminación contra las mujeres es un problema estructural que se profundiza con las dinámicas del conflicto armado, como se señaló anteriormente, y (ii) que la falta de información imposibilita la toma de decisiones y el direccionamiento de recursos para llevar a cabo acciones que permitan superar el estado actual de discriminación hacia las mujeres y la situación de vulnerabilidad que se ha empeorado a causa del conflicto armado. De esta forma, buscamos que las entidades territoriales logren ofrecer atención integral, diferenciada y pertinente que apunte a satisfacer las necesidades y particularidades de la población femenina.

La Tabla 2 (en anexos) es una tabla indicativa de las responsabilidades de las entidades territoriales por componentes y medidas de la política pública de atención y reparación integral a las víctimas respecto de la implementación de la Ley 1448 con enfoque de género y las variables que se deben tener en cuenta en los procesos de caracterización, planeación y formulación. Esta tabla permitirá a las entidades territoriales comprender la importancia de tener en cuenta las variables que afectan a las mujeres como una situación de discriminación estructural y relacionarlas con los componentes y medidas de la política pública de prevención, atención, asistencia y reparación integral a las víctimas.

El propósito de contar con esta información es poder diseñar programas y proyectos que tengan el propósito de garantizar los derechos a las víctimas con una perspectiva de género.

\section{Conclusiones}

Las transformaciones de las desigualdades estructurales en materia de género en procesos de justicia transicional para la consecución de un consenso social más equitativo supone una respuesta integral del Estado. Lo que se traduce en la capacidad de la institucionalidad de articularse a nivel nacional para, acto seguido y de acuerdo a los principios de corresponsabilidad y complementariedad, brindar apoyo a los territorios de acuerdo a sus capacidades. Como se mencionó previamente, el nivel nacional debe reconocer que hay una alta heterogeneidad en la capacidad financiera y humana en las entidades territoriales; dicha diferenciación de las capacidades territoriales supone un gran reto, pues la Ley de Víctimas no especifica cómo es que las entidades territoriales van a recibir un trato diferencial de acuerdo con sus capacidades (Castrellon, Taborda, Vargas, 2015). Sobre este punto, las herramientas de información y caracterización ela- 
boradas por el Departamento de Planeación Nacional pueden ser el puente de diálogo entre los territorios y la política nacional.

Proponemos que todo proceso de caracterización y formulación programática para la reparación de los daños de las mujeres supere aquella visión que concentra los daños de la población femenina en su integridad sexual, en la medida que dicha aproximación implica una reparación exclusivamente penal que impide transformaciones culturales, sociales y económicas de las mujeres en los territorios. Como mencionan Alviar y Jaramillo, centralizar los daños de las mujeres en la violencia sexual supone desconocer la ciudadanía económica y política de ellas y, peor aún, las excluye "de la posibilidad de negociar transformaciones más completas de su cotidianidad al insistir en que los daños padecidos se reducen a los ocasionados por la guerra y reducir los daños de la guerra a la violencia sexual." (2012).

Es importante reconocer los múltiples estudios que identifican los efectos desproporcionados de la guerra en la vida de la mujeres; sin embargo, se hace un llamado de atención para producir investigaciones empíricas que den cuenta de cómo el Estado ha materializado el enfoque de género en los programas de atención y reparación, con el fin de evaluar si las medidas adoptadas en los diferentes sistemas de reparación han logrado transformar su situación estructural de desigualdad previa al hecho victimizante. En la medida en que hoy encontramos una inmensa literatura sobre lo que significa ser mujer en medio del conflicto armado, pero poca bibliografía sobre cómo hemos materializado el enfoque de género en las políticas de justicia transicional.

Por último, cerramos advirtiendo que cualquier intento para la construcción de la paz supone formular reparaciones transformadoras para las víctimas, y en el caso de las mujeres, se traduce en la capacidad del Estado de atender y mejorar, desde las políticas públicas en la materia, el nivel de goce de sus derechos y libertades para modificar los patrones de acción y toma de decisiones de las mujeres. Y de esa manera transformar la realidad y concepción de las mujeres sobre "lo que me tocó vivir" en un país marcado por el conflicto. Para lograr que las mujeres transiten del lugar de víctimas de la guerra hacia una ciudadanía plena. 


\section{Bibliografía}

ALVIAR GARCÍA H.; Jaramillo Sierra I. C. (2012). El Análisis distributivo como alternativa crítica al legalismo liberal. Bogotá: Siglo de Hombre Editores y Universidad de Los Andes, Facultad de Derecho.

CASTRELLÓN PÉREZ, M., Taborda Burgos, J.C., Vargas Gomez, J. (2015) Los retos de los comités territoriales de justicia transicional en la implementación de la Ley de Víctimas. Revista de Derecho Público. (34). Universidad de los Andes Colombia.

CORTE CONSTITUCIONAL DE COLOMBIA. (2008). Auto 092 (Corte Constitucional de Colombia 14 de Abril de 2008).

CORTE CONSTITUCIONAL DE COLOMBIA. (2013). Auto o98 (Corte Constitucional de Colombia 21 de Mayo de 2013).

ALTA CONSEJERÍA PRESIDENCIA PARA LA EQUIDAD. (2010). Situación de las Mujeres en Colombia y en la Región de la Orinoquía- Cifras e Indicadores. Bogotá: República de Colombia.

CORTE CONSTITUCIONAL DE COLOMBIA. (2010). Situación de las mujeres en Colombiay en ChocóCifras e Indicadores. Bogotá: Presidencia de la República.

CORTE CONSTITUCIONAL DE COLOMBIA. (2012). Lineamientos de la Pólítica Pública Nacional de Equidad de Género para las Mujeres. Bogotá: Presidencia de la República.

CENTRO DE MEMORIA HISTÓRICA. (2013). !Basta Ya! Colombia: Memorias de Guerra y Dignidad. Bogotá: Centro de Memoria Histórica.

CEPAL. (2007). El aporte de las mujeres a la igualdad en América Latina y el Caribe. Conferencia Regional sobre la Mujer de América Latina y el Caribe. Quito, Ecuador: CEPAL.

CNRR-GRUPO DE MEMORIA HISTÓRICA. (2011). Mujeresy Guerra. Víctimasy resistentes en el Caribe Colombiano. Bogotá: Santillana Ediciones.

COMISIÓN COLOMBIANA DE JURISTAS (2011). La política agraria y los derechos de las mujeres en Colombia. Disponible en http://www.coljuristas.org/documentos/documento.php?grupo $=3 \&$ id_doc $=284$

COMISIÓN INTERAMERICANA DE DERECHOS HUMANOS. (2006). Las Mujeres Frente a la Violencia y la Discriminación Derivadas del Conflicto Armado en Colombia. Washington, D.C.: Organización de los Estados Americanos.

COMISIÓN INTERAMERICANA DE DERECHOS HUMANOS. (2009). Informe de Seguimiento- Las Mujeres frente a la Violencia y Discriminación Derivadas del Conflicto Armado en Colombia. Washington, D.C.: Organización de los Estados Americanos.

COMISIÓN INTERAMERICANA DE DERECHOS HUMANOS. (2010). Acceso a Servicios de salud materna desde una perspectiva de derechos. Washington: Organización de Estados Americanos. 
COMISIÓN INTERAMERICANA DE DERECHOS HUMANOS. (2011). El trabajo, la educación y los recursos de las mujeres: La ruta hacia la igualdad en la garantía de los derechos económicos, sociales y culturales. Washington: Organización de Estados Americanos.

CÓMITE DE DERECHOS ECONÓMICOS, SOCIALES Y CULTURALES. (1999). Observación General No. 3. Ginebra: Naciones Unidas.

CONGRESO DE LA REPÚBLICA DE COLOMBIA. (10 de Junio de 2011). Ley de Víctimas y Restitución de Tierras. Ley 1448 de 2011. Bogotá.

DANE. (2011). Información Básica Territorial. Bogota: https://www.dnp.gov.co/Programas/DesarrolloTerritorial/Gesti\%C3\%B3nP\%C3\%BAblicaTerritorial/Informaci\% $\mathrm{C}_{3} \% \mathrm{~B}_{3} \mathrm{nB} \% \mathrm{C}_{3} \% \mathrm{~A} 1$ sicaTerritorial.aspx.

DEERE, C. D. (2011). Tierra y autonomía económica de la mujer rural: avances y desafíos para la investigación. En P. Costas, Tierra de mujeres, reflexiones sobre el acceso de las mujeres rurales a la tierra en América Latina (pp. 41-64). México: Coalición Internacional para el Acceso a la Tierra.

DEERE, C., Lastaria-Cornhiel S \& Ranaboldo C. (2011). Tierra de mujeres. Reflexiones sobre el acceso de las mujeres rurales a la tierra en América Latina. La Paz, Bolivia: Ed. Escorpión.

INSTITUTO NACIONAL MEDICINA LEGAL Y CIENCIAS FORENSES. (2011). Informe Forense. Bogotá.

LA SILLA VACÍA. (o9 de Julio de 2013). Santos todavía no cumple la Ley de Cuotas.

LEMAITRE, J., \& Bergtora Sandvik K., (2014). Beyond Sexual Violence in Transitional Justice: Political Insecurity as a Gendered Harm. Feminist Legal Studies. 22:2433-261

MINISTERIO DE LA PROTECCIÓN SOCIAL. (2009). Primer Informe Nacional de Calidad de la Atención en Salud. Bogotá.

NACIONES UNIDAS. (Septiembre de 1995). Cuarta Conferencia Mundial sobre la Mujer. Declaración de Beijing y Plataforma de Acción. Beijing: Naciones Unidas.

ONU MUJERES. (2011). El Progreso de las Mujeres en el Mundo. New York: ONU Mujeres.

PEÑA ET. al (2013). Mujer y Movilidad Social. Documentos CEDE. ISSN 1657-7191 Edición electrónica.

PROFAMILIA. (2010). Encuesta Nacional de Demografia y Salud ENDS. Obtenido de Profamilia: http://www.profamilia.org.co/encuestas/Profamilia/Profamilia/index.php?option=com_conten$\mathrm{t} \&$ view $=$ article\&id $=66 \&$ Itemid $=49$

RELATOR ESPECIAL SOBRE EL DERECHO A LA SALUD. (2006). El derecho de toda persona al disfrute del más alto nivel posible de salud fisica y mental. Ginebra: Naciones Unidas, Asamblea General.

ROUSSET SIRI, A. J. (2011). El Concepto de Reparación Integral en la jurisprudencia de la Corte Interamericana de Derechos Humanos. Revista Internacional de Derechos Humanos, 59-79. 
RUBIO-MARIN, R., (2012). Reparations for conflicto-related sexual and reproductive violence A decalogue. William and Mary Journal of Women and the Law 19 Ñ 1(69/104)

SAVOGAL, ADRIANA, (2012). Brecha salarial entre hombres y mujeres y ciclo económico en Colombia. Coyuntura Económica Investigación Económica y Social. XLII (1), 53-91.

UNIDAD DE RESTITUCIÓN DE TIERRAS. (04 de Febrero de 2013). Solicitudes de Ingreso al Registro de Tierras Despojadas y Abandonadas Forzosamente. Recuperado el 17 de Julio de 2013, de http:// restituciondetierras.gov.co/media/descargas/estadisticas/estadisticas-20130204.pdf

UNIDAD PARA LA ATENCIÓN Y REPARACIÓN INTEGRAL A LAS VÍCTIMAS, M. d. (2O12). Guía para la Formulacióny Ajuste de los Planes de Acción Departamentales, Municipalesy distritales. Bogotá.

UPRIMNY RODRIGO, G. D. (2010). En búsqueda de un concepto transformador y participativo para las reparaciones en contextos transicionales. Revista Colombiana de Derecho Internacional, 231-286.

VARGAS, E., Ibarra, C., \& Trujillo, M. (5 de Junio de 2013). Revisión del Formato Único de Declaración para el Registro Único de Víctimas. Consultoría para el Fortalecimiento de la Unidad Administrativa Para la Atención y la Reparación Integral a las Víctimas y la Unidad de Protección en la Inclusión del Enfoque de Género y Derechos de las Mujeres. Bogotá.

WORLD HEALTH ORGANIZATION. (1999). Reduction of maternal mortality: A joint WHO/UNFPA/ UNICEF/World Bank Statement. Geneva: World Health Organization.

\section{Anexos}

TABLA 1

Niveles de caracterización

\section{Diagnóstico (PAT) ～～Programático}

$\begin{array}{ccccccc}\% & \mid & \# & \% & \# \\ \begin{array}{c}\text { No } \\ \text { abordan } \\ \text { tema }\end{array} & \begin{array}{c}\text { abordan } \\ \text { tema }\end{array} & \begin{array}{c}\text { No } \\ \text { formulan } \\ \text { programas }\end{array} & \begin{array}{c}\mathrm{Si} \\ \text { formulan } \\ \text { programas }\end{array} \\ \end{array}$

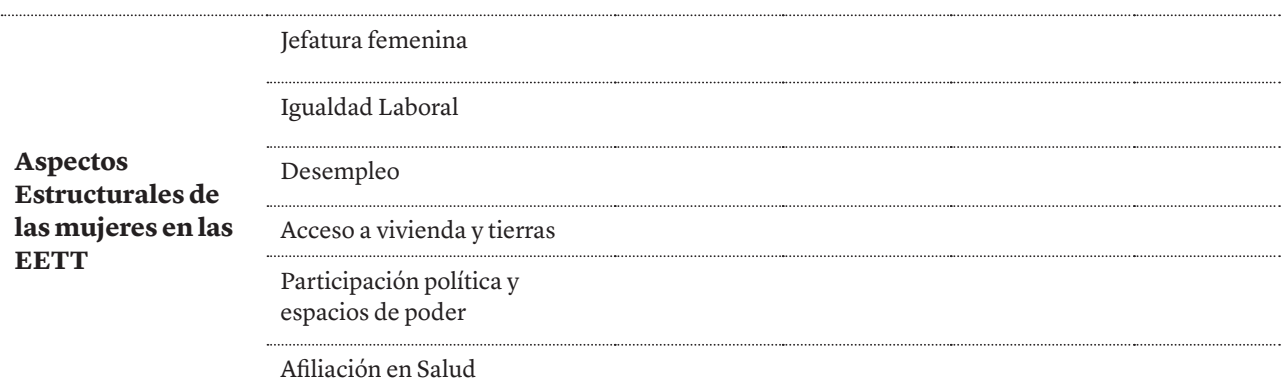




\begin{tabular}{|c|c|c|c|}
\hline & & \\
\hline & & & \\
\hline & & & IVE \\
\hline & & & VIH/SIDA \\
\hline & & & Tasa Analfabetismo \\
\hline & & & $\begin{array}{l}\text { Acceso y nivel a educación } \\
\text { primaria y secundaria }\end{array}$ \\
\hline & & & Violencia intrafamiliar \\
\hline & & & Violencia sexual \\
\hline \multirow{15}{*}{\multicolumn{2}{|c|}{$\begin{array}{l}\text { Riesgos y hechos } \\
\text { victimizantes } \\
\text { específicos de las } \\
\text { Mujeres }\end{array}$}} & & Esterilización forzada \\
\hline & & & Embarazo forzado \\
\hline & & & Aborto forzado \\
\hline & & & Prostitución forzada \\
\hline & & & Esclavitud sexual \\
\hline & & & Matrimonio forzado \\
\hline & & & $\begin{array}{l}\text { Actos sexuales forzados o } \\
\text { con amenaza en presencia } \\
\text { de miembros de la familia o } \\
\text { comunidad }\end{array}$ \\
\hline & & & $\begin{array}{l}\text { Actos sexuales forzados con } \\
\text { terceros }\end{array}$ \\
\hline & & & $\begin{array}{l}\text { Observar y presenciar } \\
\text { forzadamente actos sexuales }\end{array}$ \\
\hline & & & Mutilaciones \\
\hline & & & Desnudez forzada \\
\hline & & & $\begin{array}{l}\text { Inspecciones genitales/anales } \\
\text { forzadas }\end{array}$ \\
\hline & & & Servicio doméstico forzado \\
\hline & & & Prácticas degradantes \\
\hline & & & Otros \\
\hline
\end{tabular}


TABLA 2

Asistencia

Derechos de las víctimas con énfasis en las mujeres/Reglamentación correspondiente
Responsabilidad de la entidad territorial
Variables para la caracterización de las mujeres $\mid$ para la caracteriniñas víctimas zación

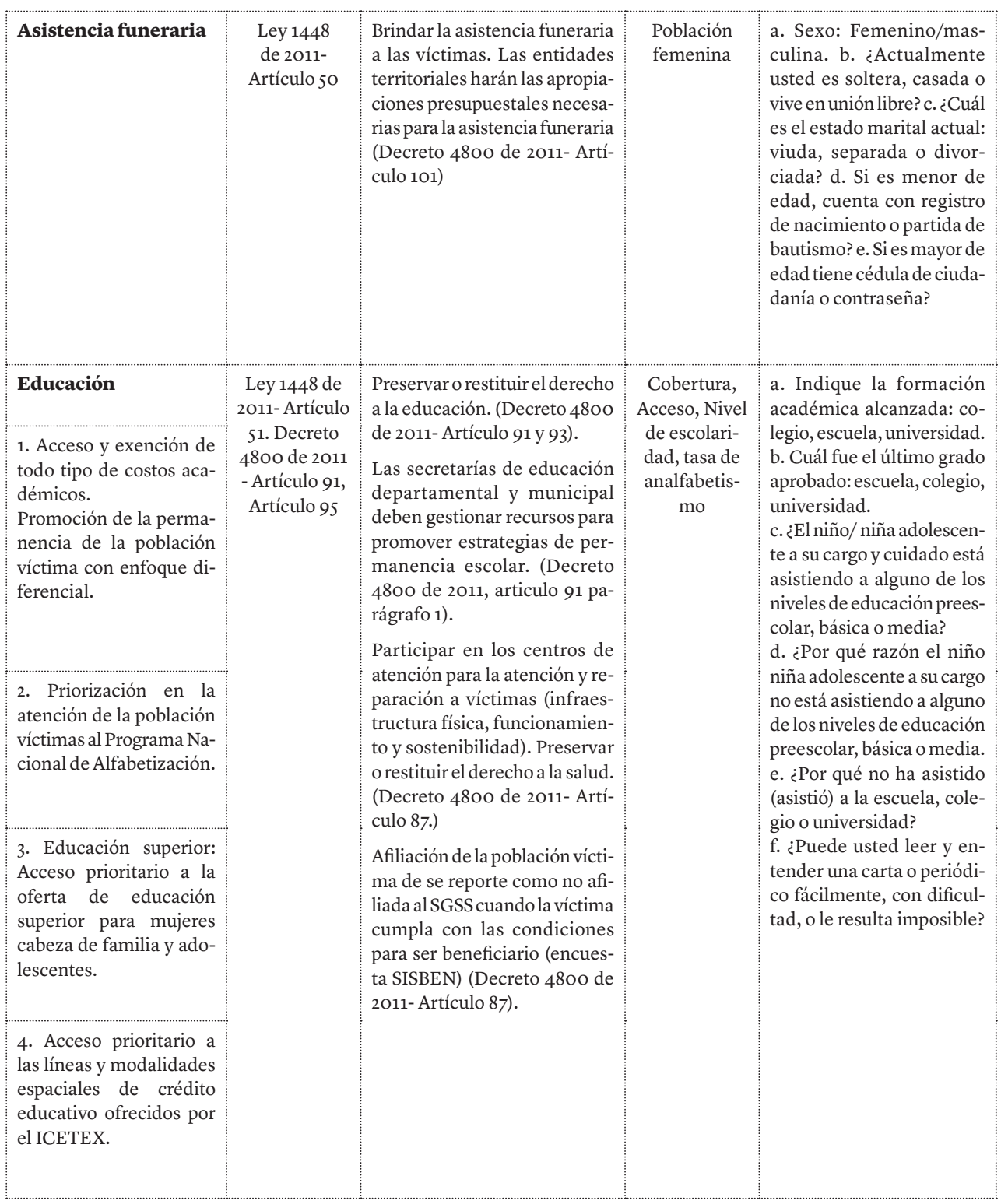




\begin{tabular}{|c|c|c|c|}
\hline Salud & \multirow{5}{*}{$\begin{array}{l}\text { Ley } 1448 \text { de } \\
\text { 2011- Artículo } \\
53 \text {, Artículo } \\
54 \text { y Artículo } \\
55 \text {. Decreto } \\
4800 \text { de } 2011 \\
\text { - Artículo } 87\end{array}$} & \multirow{5}{*}{$\begin{array}{c}\text { Tipo de } \\
\text { afiliación } \\
\text { (contributivo y } \\
\text { subsidiados); } \\
\text { salud sexual y } \\
\text { reproductiva: } \\
\text { embarazo ado- } \\
\text { lescente; VIH; } \\
\text { IVE; mortali- } \\
\text { dad materna. }\end{array}$} & \multirow{5}{*}{$\begin{array}{l}\text { a. ¿Se encuentra afiliada al } \\
\text { SGSSS en alguna de las si- } \\
\text { guientes modalidades?: (EPS } \\
\text { Contributivo/EPS- subsidia- } \\
\text { do/ EPS- subsidiado - cajas } \\
\text { de compensación/ EPS- subsi- } \\
\text { diado-indígenas/ EPS- subsi- } \\
\text { diado-solidarias/ Regímenes } \\
\text { especiales/SISBEN/ No afilia- } \\
\text { do/ Carta de desplazado/ No } \\
\text { cuenta con información-pen- } \\
\text { diente verificación). } \\
\text { b. ¿Actualmente usa algún } \\
\text { método de anticoncepción? } \\
\text { Indique cuál. ¿Tiene acceso a } \\
\text { métodos de anticoncepción? } \\
\text { c. ¿En la actualidad es madre } \\
\text { gestante?, ¿se encuentra en } \\
\text { estado de embarazo?, ¿Usted } \\
\text { tiene un embarazo producto } \\
\text { de un acto sexual abusivo? } \\
\text { d. ¿En la actualidad es madre } \\
\text { lactante? } \\
\text { e. ¿Cuál es su edad? Según lo } \\
\text { que usted ha vivido por el con- } \\
\text { flicto armado y lo que este le } \\
\text { ha generado emocionalmente } \\
\text { o en las relaciones con su fa- } \\
\text { milia: ¿considera que requiere } \\
\text { acompañamiento psicosocial } \\
\text { o atención psicológica? } \\
\text { f. Para mujeres que denuncian } \\
\text { un episodio de violencia se- } \\
\text { xual: preguntar si a la fecha le } \\
\text { han sugerido/o se ha realizado } \\
\text { una prueba para saber si tiene } \\
\text { el virus que causa el SIDA y/o } \\
\text { enfermedades de transmisión } \\
\text { sexual posterior al hecho victi- } \\
\text { mizante. ¿Sabe Usted los resul- } \\
\text { tados de las pruebas? }\end{array}$} \\
\hline $\begin{array}{l}\text { 1. Atención en emer- } \\
\text { gencias }\end{array}$ & & & \\
\hline $\begin{array}{l}\text { 2. Servicios de asis- } \\
\text { tencia en salud }\end{array}$ & & & \\
\hline 3. Remisiones & & & \\
\hline $\begin{array}{l}\text { 4. Afiliación de víc- } \\
\text { timas al Sistema Ge- } \\
\text { neral de Seguridad } \\
\text { Social en Salud }\end{array}$ & & & \\
\hline
\end{tabular}


Ayuda Humanitaria (Población Desplazada)

Derechos de las víctimas con énfasis en las mujeres/Reglamentación correspondiente

\section{Responsabilidad} de la entidad territorial
Variables para la caracterización de las mujeres y niñas víctimas
Preguntas guía para la caracterización

\begin{tabular}{|c|c|c|c|c|}
\hline \multirow[t]{2}{*}{$\begin{array}{l}\text { Atención } \\
\text { Inmediata }\end{array}$} & \multirow[t]{2}{*}{$\begin{array}{c}\text { Ley } 1448 \\
\text { de } 2011 \text { - } \\
\text { Artículo } \\
\text { 63. Decreto } \\
4800 \text { de } \\
2011 \text { - } \\
\text { Artículo 108 }\end{array}$} & \multirow{2}{*}{$\begin{array}{l}\text { Suministrar la atención hu- } \\
\text { manitaria inmediata a la po- } \\
\text { blación en situación de des- } \\
\text { plazamiento (alimentación, } \\
\text { aseo personal, manejo de } \\
\text { abastecimientos, utensilios } \\
\text { de cocina y alojamiento tran- } \\
\text { sitorio). Mientras se realiza el } \\
\text { trámite de inscripción en el } \\
\text { Registro Único de Víctimas. } \\
\text { (Decreto } 4800 \text { de 2o11- Artí- } \\
\text { culo 106 y 108). } \\
\text { Conjuntamente con la UA- } \\
\text { RIV y el ICBF garantizar la } \\
\text { entrega de ayuda humanita- } \\
\text { ria a las víctimas de despla- } \\
\text { zamiento forzado que ya han } \\
\text { sido registradas en el RUV. } \\
\text { (Decreto } 4800 \text { de } 2011-\text { Ar- } \\
\text { tículo 1o9, 11o y 111). } \\
\text { Junto con el ICBF y la UA- } \\
\text { RIV, los entes territoriales } \\
\text { deben adoptar las medidas } \\
\text { necesarias para garantizar el } \\
\text { alojamiento temporal de la } \\
\text { población que se encuentre } \\
\text { en la fase de atención huma- } \\
\text { nitaria de transición. (De- } \\
\text { creto } 4800 \text { de } 2011-\text { Artículo } \\
\text { 116) Articular e implementar } \\
\text { acciones para la generación } \\
\text { de ingresos de la población } \\
\text { que ha sido desplazada. } \\
\text { Articular e implementar ac- } \\
\text { ciones para la vivienda digna } \\
\text { de la población que ha sido } \\
\text { desplazada. }\end{array}$} & $\begin{array}{l}\text { Población } \\
\text { femenina }\end{array}$ & $\begin{array}{l}\text { a. Sexo: Femenino/masculina b. } \\
\text { ¿Actualmente usted es soltera, } \\
\text { casada o vive en unión libre? c. } \\
\text { ¿Cuál es el estado marital actual: } \\
\text { viuda, separada o divorciada? d. } \\
\text { Si es menor de edad, cuenta con } \\
\text { registro de nacimiento o partida } \\
\text { de bautismo? e. Si es mayor de } \\
\text { edad tiene cédula de ciudadanía } \\
\text { o contraseña? }\end{array}$ \\
\hline & & & $\begin{array}{l}\text { Autonomía } \\
\text { económica: } \\
\text { igualdad laboral, } \\
\text { Informalidad } \\
\text { laboral y } \\
\text { desempleo }\end{array}$ & $\begin{array}{l}\text { a. ¿Cuál era su actividad antes de } \\
\text { la ocurrencia del hecho victimi- } \\
\text { zante? } \\
\text { b. ¿Con qué estaba relacionada la } \\
\text { actividad que desempeñaba? } \\
\text { c. ¿Cuál es la principal fuente de } \\
\text { ingresos de su hogar? } \\
\text { d. ¿Es usted la única proveedora } \\
\text { económica del hogar? } \\
\text { e. Además del trabajo del hogar, } \\
\text { ¿actualmente Ud. tiene otro tra- } \\
\text { bajo? }\end{array}$ \\
\hline
\end{tabular}




\begin{tabular}{|c|c|c|c|c|}
\hline & & & $\begin{array}{l}\text { Salud integral: } \\
\text { afiliación al } \\
\text { sistema de salud, } \\
\text { acceso a métodos } \\
\text { de planificación, } \\
\text { embarazos } \\
\text { adolescentes, } \\
\text { IVE, VIH, } \\
\text { mortalidad } \\
\text { materna y salud } \\
\text { mental. }\end{array}$ & $\begin{array}{l}\text { Escribir nuevamente las pregun- } \\
\text { tas de caracterización }\end{array}$ \\
\hline & & & $\begin{array}{l}\text { Educación: tasa } \\
\text { de analfabetismo, } \\
\text { acceso y nivel. }\end{array}$ & $\begin{array}{l}\text { Escribir nuevamente las pregun- } \\
\text { tas de caracterización }\end{array}$ \\
\hline & & & $\begin{array}{l}\text { Violencia contra } \\
\text { las mujeres }\end{array}$ & $\begin{array}{l}\text { a. ¿Cuáles de estas dificultades } \\
\text { se mantienen hoy en día en su } \\
\text { familia? (Situación de violencia } \\
\text { intrafamiliar, cambios intempes- } \\
\text { tivos de roles masculinos-feme- } \\
\text { ninos que no son asimilables por } \\
\text { la familia). } \\
\text { b. ¿Su (ex)esposo / (ex)compañe- } \\
\text { ro la ha amenazado (amenazó) } \\
\text { alguna vez con abandonarla, qui- } \\
\text { tarle los hijos y/o quitarle apoyo } \\
\text { económico? } \\
\text { c. ¿Alguna vez su (ex)compañe- } \\
\text { ro / (ex)esposo la ha empujado, } \\
\text { golpeado, amenazado con algún } \\
\text { objeto, la ha forzado físicamente } \\
\text { a tener relaciones o actos sexua- } \\
\text { les que Ud. no quería? } \\
\text { d. ¿Alguna vez ha sido forzada } \\
\text { físicamente por alguna persona } \\
\text { (diferentes a su esposo / compa- } \\
\text { ñero) a tener relaciones o actos } \\
\text { sexuales? }\end{array}$ \\
\hline $\begin{array}{l}\text { Atención de } \\
\text { emergencia }\end{array}$ & $\begin{array}{c}\text { Ley } 1448 \\
\text { de } 2011^{-} \\
\text {Artículo } \\
\text { 64. Decreto } \\
4800 \\
\text { de } 2011^{-} \\
\text {Artículo } 109\end{array}$ & \multirow{2}{*}{$\begin{array}{l}\text { A pesar de que tanto la ayu- } \\
\text { da de emergencia como } \\
\text { de transición están a cargo } \\
\text { de la Unidad de Víctimas, } \\
\text { debido a que las víctimas } \\
\text { de desplazamiento forzado } \\
\text { se encuentras en distintas } \\
\text { EE.TT., estas deben propen- } \\
\text { der por lograr una entrega } \\
\text { coordinada y eficiente de la } \\
\text { ayuda humanitaria de emer- } \\
\text { gencia y transición }\end{array}$} & & \\
\hline $\begin{array}{l}\text { Atención de } \\
\text { transición }\end{array}$ & $\begin{array}{c}\text { Ley } 1448 \\
\text { de } 2011- \\
\text { Artículo } \\
65 . \text { Decreto } \\
4800 \\
\text { de } 2011- \\
\text { Artículo } 112\end{array}$ & & & \\
\hline
\end{tabular}


Ayuda Humanitaria (Víctimas de hechos diferentes al desplazamiento forzado)

Derechos de las víctimas con énfasis en las mujeres/Reglamentación correspondiente
Responsabilidad de la entidad territorial
Variables para la caracterización de las mujeres y $\quad$ para la caracteriniñas víctimas zación

\begin{tabular}{|c|c|c|c|c|}
\hline \multirow{2}{*}{$\begin{array}{l}\text { Entrega } \\
\text { de ayuda } \\
\text { humanitaria } \\
\text { de acuerdo con } \\
\text { las necesidades } \\
\text { de cada hecho } \\
\text { victimizante. } \\
{ }^{*} \text { Las víctimas } \\
\text { de los delitos } \\
\text { contra la } \\
\text { libertad, } \\
\text { integridad } \\
\text { y formación } \\
\text { sexual recibirán } \\
\text { asistencia } \\
\text { médica y } \\
\text { psicológica de } \\
\text { emergencia. }\end{array}$} & \multirow[t]{3}{*}{$\begin{array}{c}\text { Ley } 1448 \\
\text { de } 2011 \text { - } \\
\text { Artículo } \\
47 . \text { Decreto } \\
4800 \text { de } \\
2011 \text { - } \\
\text { Artículo } \\
102\end{array}$} & \multirow[t]{3}{*}{$\begin{array}{l}\text { Suministrar la ayuda humani- } \\
\text { taria inmediata a la población } \\
\text { de otros hechos victimizantes } \\
\text { por un mes (alimentación, aseo } \\
\text { personal, manejo de abasteci- } \\
\text { mientos, utensilios de cocina, } \\
\text { atención médica y psicológica } \\
\text { de emergencia, transporte de } \\
\text { emergencia y alojamiento tran- } \\
\text { sitorio). Es prorrogable por un } \\
\text { mes adicional en caso de vul- } \\
\text { nerabilidad derivada del hecho } \\
\text { victimizante. }\end{array}$} & $\begin{array}{l}\text { Población } \\
\text { femenina }\end{array}$ & $\begin{array}{l}\text { Escribir nuevamente las pregun- } \\
\text { tas de caracterización }\end{array}$ \\
\hline & & & $\begin{array}{l}\text { Jefatura } \\
\text { femenina }\end{array}$ & $\begin{array}{l}\text { Escribir nuevamente las pregun- } \\
\text { tas de caracterización }\end{array}$ \\
\hline & & & Salud Integral & $\begin{array}{l}\text { Escribir nuevamente las pregun- } \\
\text { tas de caracterización }\end{array}$ \\
\hline
\end{tabular}


Restitución de Tierras

Derechos de las víctimas con énfasis en las mujeres/Reglamentación correspondiente
Responsabilidad de la entidad territorial
Variables para la caracterización de las mujeres y niñas víctimas
Preguntas guía para la caracterización

\begin{tabular}{|c|c|c|c|c|}
\hline $\begin{array}{l}\text { Acciones de } \\
\text { restitución a } \\
\text { favor de los } \\
\text { despojados. } \\
\text { Priorización de } \\
\text { los padres y las } \\
\text { madres cabeza } \\
\text { de familia } \\
\text { en el análisis } \\
\text { previo de las } \\
\text { solicitudes de } \\
\text { registro }\end{array}$ & $\begin{array}{c}\text { Ley } 1448 \\
\text { de } 2011^{-} \\
\text {Artículo } \\
\text { 72. Decreto } \\
4829 \text { de } \\
\text { 2011- } \\
\text { Artículo } 9\end{array}$ & $\begin{array}{l}\text { Articular el subcomité de resti- } \\
\text { tución de tierras y la instancia } \\
\text { territorial (Comité de Justicia } \\
\text { Transicional), en el marco de } \\
\text { la definición de medidas de } \\
\text { seguridad. }\end{array}$ & $\begin{array}{l}\text { Población } \\
\text { femenina }\end{array}$ & $\begin{array}{l}\text { Escribir nuevamente las pregun- } \\
\text { tas de caracterización }\end{array}$ \\
\hline \multirow{3}{*}{$\begin{array}{l}\text { Atención } \\
\text { preferencial } \\
\text { para las mujeres } \\
\text { en los procesos } \\
\text { de restitución. } \\
\text { Titulación de } \\
\text { la propiedad y } \\
\text { restitución de } \\
\text { derechos }\end{array}$} & \multirow[t]{3}{*}{$\begin{array}{l}\text { Ley } 1448 \\
\text { de } 2011- \\
\text { Artículo } \\
114,115 \text { y } \\
118\end{array}$} & & $\begin{array}{l}\text { Jefatura } \\
\text { femenina }\end{array}$ & $\begin{array}{l}\text { Escribir nuevamente las pregun- } \\
\text { tas de caracterización }\end{array}$ \\
\hline & & & $\begin{array}{c}\text { Autonomía } \\
\text { económica: } \\
\text { informalidad } \\
\text { laboral y } \\
\text { desempleo. }\end{array}$ & $\begin{array}{l}\text { Escribir nuevamente las pregun- } \\
\text { tas de caracterización }\end{array}$ \\
\hline & & & $\begin{array}{c}\text { Acceso a } \\
\text { vivienda y } \\
\text { tierras }\end{array}$ & $\begin{array}{l}\text { Escribir nuevamente las pregun- } \\
\text { tas de caracterización }\end{array}$ \\
\hline
\end{tabular}


Restitución de Vivienda

\section{Derechos de las vícti-} mas con énfasis en las mujeres/Reglamentación correspondiente
Responsabilidad

de la entidad territorial
Variables para la caracterización de las mujeres y niñas víctimas
Preguntas guía para la caracterización

\begin{tabular}{|c|c|c|c|c|}
\hline $\begin{array}{l}\text { Prioridad y acceso } \\
\text { preferente a } \\
\text { programas de } \\
\text { subsidios de } \\
\text { vivienda cuando } \\
\text { las víctimas hayan } \\
\text { sido afectadas } \\
\text { por despojo, }\end{array}$ & $\begin{array}{l}\text { Ley } 1448 \\
\text { de } 2011^{-} \\
\text {Artículo } \\
\text { 123. } \\
\text { Decreto } \\
4829 \text { de } \\
2011- \\
\text { Artículo }\end{array}$ & $\begin{array}{l}\text { En aplicación de los principios } \\
\text { de coordinación, concurrencia } \\
\text { y subsidiaridad, facilitar el cie- } \\
\text { rre financiero de las soluciones } \\
\text { habitacionales para los hogares } \\
\text { víctimas, pérdida, abandono, } \\
\text { despojo y menoscabo de sus } \\
\text { viviendas. Así como generar }\end{array}$ & $\begin{array}{l}\text { Población } \\
\text { femenina }\end{array}$ & $\begin{array}{l}\text { Escribir nuevamente las pre- } \\
\text { guntas de caracterización }\end{array}$ \\
\hline $\begin{array}{l}\text { abandono, pérdida } \\
\text { o menoscabo } \\
\text { de la vivienda. } \\
\text { Teniendo } \\
\text { en cuenta la } \\
\text { población que } \\
\text { se encuentra } \\
\text { en situación } \\
\text { de debilidad } \\
\text { manifiesta como }\end{array}$ & 131 y 133 & $\begin{array}{l}\text { alternativas que incentiven el } \\
\text { desarrollo y ejecución de pro- } \\
\text { yectos de vivienda para pobla- } \\
\text { ción víctima. (Decreto } 4800 \text { de } \\
\text { 2011- Artículo 135). }\end{array}$ & $\begin{array}{c}\text { Autonomía } \\
\text { económica: } \\
\text { informalidad } \\
\text { laboral y } \\
\text { desempleo. }\end{array}$ & $\begin{array}{l}\text { Escribir nuevamente las pre- } \\
\text { guntas de caracterización }\end{array}$ \\
\hline $\begin{array}{l}\text { prioritaria. } \\
{ }^{* *} \text { Mujeres cabeza } \\
\text { de familia. }\end{array}$ & & & $\begin{array}{c}\text { Acceso a } \\
\text { vivienda y } \\
\text { tierras }\end{array}$ & $\begin{array}{l}\text { Escribir nuevamente las pre- } \\
\text { guntas de caracterización }\end{array}$ \\
\hline
\end{tabular}


Formación, generación de empleo y carrera administrativa

Derechos de las víctimas con énfasis en las mujeres/Reglamentación correspondiente
Responsabilidad de la entidad territorial
Variables para la caracterización de las mujeres y niñas víctimas
Preguntas guía para la caracterización

\begin{tabular}{|c|c|c|c|}
\hline $\begin{array}{l}\text { Capacitación } \\
\text { y planes de } \\
\text { empleo urbanoy } \\
\text { rural: Prioridad } \\
\text { y facilidad } \\
\text { para el acceso } \\
\text { de jóvenes y } \\
\text { adultos víctimas } \\
\text { al SENA. } \\
\text { Programa de } \\
\text { generación de } \\
\text { empleo rural y } \\
\text { urbano } \\
\text { Derecho } \\
\text { preferencial } \\
\text { de acceso a } \\
\text { la carrera } \\
\text { administrativa }\end{array}$ & $\begin{array}{c}\text { Ley } 1448 \\
\text { de } 2011- \\
\text { Artículo } \\
130 . \\
\text { Decreto } \\
4829 \text { de } \\
2011^{-} \\
\text {Artículo } \\
67,68\end{array}$ & $\begin{array}{l}\text { Población } \\
\text { femenina }\end{array}$ & $\begin{array}{l}\text { Escribir nuevamente las pregun- } \\
\text { tas de caracterización }\end{array}$ \\
\hline \multirow{2}{*}{$\begin{array}{l}\text { Derecho } \\
\text { preferencial } \\
\text { de acceso a } \\
\text { la carrera } \\
\text { administrativa }\end{array}$} & \multirow{2}{*}{$\begin{array}{c}\text { Ley } 1448 \\
\text { de } 2011^{-} \\
\text {Artículo } \\
131\end{array}$} & $\begin{array}{l}\text { Jefatura } \\
\text { femenina }\end{array}$ & $\begin{array}{l}\text { Escribir nuevamente las pregun- } \\
\text { tas de caracterización }\end{array}$ \\
\hline & & $\begin{array}{c}\text { Autonomía } \\
\text { económica: } \\
\text { informalidad } \\
\text { laboral y } \\
\text { desempleo. }\end{array}$ & $\begin{array}{l}\text { Escribir nuevamente las pregun- } \\
\text { tas de caracterización }\end{array}$ \\
\hline
\end{tabular}


Indemnización administrativa

Derechos de las víctimas con énfasis en las mujeres/Reglamentación correspondiente
Responsabilidad

de la entidad territorial
Variables para la caracterización de las mujeres y niñas víctimas
Preguntas guía para la caracterización

\begin{tabular}{|c|c|c|c|c|}
\hline $\begin{array}{l}\text { Entrega de } \\
\text { un monto } \\
\text { indemnizatorio } \\
\text { cuyo valor } \\
\text { depende del hecho } \\
\text { victimizante }\end{array}$ & $\begin{array}{c}\text { Ley } 1448 \\
\text { de } 2011- \\
\text { Artículo } \\
132 . \\
\text { Decreto } \\
4829 \text { de } \\
2011- \\
\text { Artículo } \\
149\end{array}$ & $\begin{array}{l}\text { Participación en la ejecución } \\
\text { del Programa de acompaña- } \\
\text { miento para la inversión ade- } \\
\text { cuada de los recursos }\end{array}$ & $\begin{array}{l}\text { Población } \\
\text { femenina }\end{array}$ & $\begin{array}{l}\text { Escribir nuevamente las pre- } \\
\text { guntas de caracterización }\end{array}$ \\
\hline \multirow[t]{3}{*}{$\begin{array}{l}\text { Programa de } \\
\text { acompañamiento }\end{array}$} & $\begin{array}{c}\text { Ley } 1448 \\
\text { de } 2011- \\
\text { Artículo } \\
134 \cdot \\
\text { Decreto } \\
4829 \text { de } \\
2011- \\
\text { Artículo } \\
157,158\end{array}$ & & $\begin{array}{c}\text { Autonomía } \\
\text { económica: } \\
\text { informalidad } \\
\text { laboral y } \\
\text { desempleo. }\end{array}$ & $\begin{array}{l}\text { Escribir nuevamente las pre- } \\
\text { guntas de caracterización }\end{array}$ \\
\hline & & & $\begin{array}{l}\text { Educación: } \\
\text { tasa de } \\
\text { analfabetismo, } \\
\text { acceso y nivel. }\end{array}$ & $\begin{array}{l}\text { Escribir nuevamente las pre- } \\
\text { guntas de caracterización }\end{array}$ \\
\hline & & & $\begin{array}{c}\text { Acceso a } \\
\text { vivienda y } \\
\text { tierras }\end{array}$ & $\begin{array}{l}\text { Escribir nuevamente las pre- } \\
\text { guntas de caracterización }\end{array}$ \\
\hline
\end{tabular}


Rehabilitación Psicosocial

Derechos de las víctimas con énfasis en las mujeres/Reglamentación correspondiente
Responsabilidad de la entidad territorial
Variables para la caracterización de las mujeres y niñas víctimas
Preguntas guía para la caracterización

\begin{tabular}{|c|c|c|c|c|}
\hline \multirow[t]{3}{*}{$\begin{array}{l}\text { Programa } \\
\text { de atención } \\
\text { psicosocial y } \\
\text { salud integral a } \\
\text { víctimas }\end{array}$} & \multirow{3}{*}{$\begin{array}{c}\text { Ley } 1448 \\
\text { de } 2011^{-} \\
\text {Artículo } \\
135 . \\
\text { Decreto } \\
4829 \text { de } \\
2011- \\
\text { Artículo } \\
164\end{array}$} & \multirow{3}{*}{$\begin{array}{l}\text { Adoptar los lineamientos del } \\
\text { Programa de Atención Psi- } \\
\text { cosocial y Salud Integral a las } \\
\text { Víctimas en concordancia con } \\
\text { lo establecido en el artículo } 174 \\
\text { de la Ley } 1448 \text { de } 2011 \text {. } \\
\text { Definir programas de atención } \\
\text { psicosocial y atención en sa- } \\
\text { lud integral, medidas de reha- } \\
\text { bilitación física a las víctimas } \\
\text { en articulación con las políti- } \\
\text { cas del Ministerio de Salud } \\
\text { y el ICBF y en la perspectiva } \\
\text { diferencial para niños, niñas, } \\
\text { adolescentes, personas con } \\
\text { discapacidad y mujeres. }\end{array}$} & $\begin{array}{l}\text { Población } \\
\text { femenina }\end{array}$ & $\begin{array}{l}\text { Escribir nuevamente las pregun- } \\
\text { tas de caracterización }\end{array}$ \\
\hline & & & Salud Integral & $\begin{array}{l}\text { Escribir nuevamente las pregun- } \\
\text { tas de caracterización }\end{array}$ \\
\hline & & & $\begin{array}{l}\text { Violencia contra } \\
\text { las mujeres }\end{array}$ & $\begin{array}{l}\text { Escribir nuevamente las pregun- } \\
\text { tas de caracterización }\end{array}$ \\
\hline
\end{tabular}


Satisfacción y Reparación Simbólica

Derechos de las víctimas con énfasis en las mujeres/Reglamentación correspondiente
Responsabilidad de la entidad territorial
Variables para la caracterización de las mujeres y niñas víctimas
Preguntas guía para la caracterización

\begin{tabular}{|c|c|c|c|c|}
\hline $\begin{array}{l}\text { Medidas de } \\
\text { satisfacción } \\
\text { con enfoque } \\
\text { diferencial }\end{array}$ & $\begin{array}{c}\text { Ley } 1448 \\
\text { de } 2011- \\
\text { Artículo } \\
139\end{array}$ & \multirow{4}{*}{$\begin{array}{l}\text { Los Comités de Justicia Transi- } \\
\text { cional elaborarán los criterios } \\
\text { que deban tener las medidas de } \\
\text { satisfacción que se ejecutarán } \\
\text { en territorio, para lo cual la Uni- } \\
\text { dad para las Víctimas brindará } \\
\text { la asistencia técnica necesaria. } \\
\text { (Decreto 48oo de 2011- Artícu- } \\
\text { lo 171 y 172). } \\
\text { Los CTJT deberán hacer segui- } \\
\text { miento a la implementación de } \\
\text { las medidas de satisfacción en } \\
\text { su municipio, distrito o depar- } \\
\text { tamento. (Decreto } 4800 \text { de } \\
\text { 2011- Artículo 172). } \\
\text { Los CTJT podrán establecer fe- } \\
\text { chas para honrar a las víctimas } \\
\text { y realizar eventos sobre memo- } \\
\text { ria histórica y solidaridad con } \\
\text { ellos (Decreto } 4800 \text { de } 2011- \\
\text { Artículo 185). } \\
\text { Los entes territoriales en virtud } \\
\text { de los principios de autonomía } \\
\text { y descentralización podrán } \\
\text { desarrollar iniciativas relacio- } \\
\text { nadas con la construcción de } \\
\text { la memoria (Ley } 1448 \text { de 2011 } \\
\text { - Artículo 144). }\end{array}$} & $\begin{array}{l}\text { Población } \\
\text { femenina }\end{array}$ & $\begin{array}{l}\text { Escribir nuevamente las pre- } \\
\text { guntas de caracterización. }\end{array}$ \\
\hline $\begin{array}{l}\text { Reparación } \\
\text { simbólica }\end{array}$ & $\begin{array}{c}\text { Ley } 1448 \\
\text { de } 2011- \\
\text { Artículo } \\
141\end{array}$ & & $\begin{array}{l}\text { Violencia contra } \\
\text { las mujeres }\end{array}$ & \multirow[t]{3}{*}{$\begin{array}{l}\text { Escribir nuevamente las pre- } \\
\text { guntas de caracterización. }\end{array}$} \\
\hline $\begin{array}{l}\text { Día Nacional } \\
\text { de Memoria y } \\
\text { Solidaridad con } \\
\text { las Víctimas }\end{array}$ & $\begin{array}{c}\text { Ley } 1448 \\
\text { de } 2011- \\
\text { Artículo } \\
142\end{array}$ & & & \\
\hline $\begin{array}{l}\text { Deber de memoria } \\
\text { Archivos sobre } \\
\text { violaciones a } \\
\text { los Derechos } \\
\text { Humanos }\end{array}$ & $\begin{array}{c}\text { Ley } 1448 \\
\text { de } 2011- \\
\text { Artículo } \\
143\end{array}$ & & & \\
\hline
\end{tabular}




\section{Reparación Colectiva}

Derechos de las víctimas con énfasis en las mujeres/Reglamentación correspondiente
Responsabilidad de la entidad territorial
Variables para la caracterización de las mujeres y niñas víctimas
Preguntas guía para la caracterización

\begin{tabular}{|c|c|c|c|c|}
\hline \multirow[t]{4}{*}{$\begin{array}{l}\text { Programa de } \\
\text { Reparación } \\
\text { Colectiva }\end{array}$} & \multirow{4}{*}{$\begin{array}{c}\text { Ley } 1448 \\
\text { de } 2011- \\
\text { Artículo } \\
151 . \\
\text { Decreto } \\
4800 \text { de } \\
2001, \\
\text { Artículos } \\
222,224\end{array}$} & \multirow{4}{*}{$\begin{array}{l}\text { Todas las instituciones del } \\
\text { Estado, a nivel nacional, re- } \\
\text { gional y local que hacen parte } \\
\text { del proceso de construcción e } \\
\text { implementación de los planes } \\
\text { de reparación colectiva, deben } \\
\text { recibir formación sobre repa- } \\
\text { ración colectiva, impactos y } \\
\text { daños colectivos, enfoque y } \\
\text { alcance del programa, acción } \\
\text { sin daño, la ruta operativa y los } \\
\text { sujetos de reparación colectiva } \\
\text { con los cuales se adelantarán en } \\
\text { la zona estos procedimientos. } \\
\text { (Decreto } 4800 \text { de 2011- Artí- } \\
\text { culo 228). } \\
\text { Aprobar el Plan de Repara- } \\
\text { ción Colectiva en el marco del } \\
\text { Comité Territorial de Justicia } \\
\text { Transicional, según correspon- } \\
\text { da. (Decreto 48oo de 2o11-Ar- } \\
\text { tículo 23o). }\end{array}$} & $\begin{array}{l}\text { Población } \\
\text { femenina }\end{array}$ & $\begin{array}{l}\text { Escribir nuevamente las pregun- } \\
\text { tas de caracterización }\end{array}$ \\
\hline & & & Salud Integral & $\begin{array}{l}\text { Escribir nuevamente las pregun- } \\
\text { tas de caracterización }\end{array}$ \\
\hline & & & $\begin{array}{l}\text { Educación: } \\
\text { tasa de } \\
\text { analfabetismo, } \\
\text { acceso y nivel. }\end{array}$ & $\begin{array}{l}\text { Escribir nuevamente las pregun- } \\
\text { tas de caracterización }\end{array}$ \\
\hline & & & $\begin{array}{l}\text { Violencia contra } \\
\text { las mujeres }\end{array}$ & $\begin{array}{l}\text { Escribir nuevamente las pregun- } \\
\text { tas de caracterización }\end{array}$ \\
\hline
\end{tabular}


Prevención, Protección y Garantías de No Repetición

Derechos de las víctimas con énfasis en las mujeres/Reglamentación correspondiente
Responsabilidad

de la entidad

territorial
Variables para la caracterización de las mujeres y niñas víctimas
Preguntas guía para la caracterización

\begin{tabular}{|c|c|c|c|c|}
\hline $\begin{array}{l}\text { Prevención: } \\
\text { adopción de } \\
\text { las medidas } \\
\text { necesarias } \\
\text { para evitar la } \\
\text { ocurrencia de } \\
\text { violaciones a los } \\
\text { DDHH. }\end{array}$ & $\begin{array}{c}\text { Ley } 1448 \\
\text { de } 2011^{-} \\
\text {Artículo } \\
\text { 149 d), k) y } \\
\text { p). Decreto } \\
4800 \\
\text { de } 2011^{-} \\
\text {Artículo } \\
193\end{array}$ & $\begin{array}{l}\text { Construir y poner en marcha } \\
\text { planes integrales de prevención } \\
\text { y planes de contingencia. (De- } \\
\text { creto } 4800 \text { de } 2011 \text { - Artículo } \\
2 \mathrm{O} 2 \text { y } 2 \mathrm{O} 3 \text { ). }\end{array}$ & $\begin{array}{l}\text { Población } \\
\text { femenina }\end{array}$ & $\begin{array}{l}\text { Escribir nuevamente las pre- } \\
\text { guntas de caracterización. }\end{array}$ \\
\hline $\begin{array}{l}\text { Protección: } \\
\text { Adopción } \\
\text { de medidas } \\
\text { especiales para } \\
\text { personas, grupos } \\
\text { o comunidades } \\
\text { en situación } \\
\text { de riesgo } \\
\text { extraordinario } \\
\text { o extremo } \\
\text { con enfoque } \\
\text { diferencial }\end{array}$ & $\begin{array}{l}\text { Decreto } \\
4800 \\
\text { de } 2011- \\
\text { Artículo } \\
195 \text { y } 212\end{array}$ & & $\begin{array}{l}\text { Violencia contra } \\
\text { las mujeres }\end{array}$ & $\begin{array}{l}\text { Escribir nuevamente las pre- } \\
\text { guntas de caracterización. }\end{array}$ \\
\hline $\begin{array}{l}\text { GNR: Adopción } \\
\text { de programas y } \\
\text { proyectos de no } \\
\text { repetición para } \\
\text { que las víctimas } \\
\text { no vuelvan a } \\
\text { sufrir violaciones } \\
\text { a sus DDHH }\end{array}$ & $\begin{array}{c}\text { Ley } 1448 \\
\text { de } 2011- \\
\text { Artículo } \\
149 . \\
\text { Decreto } \\
4800 \\
\text { de } 2011- \\
\text { Artículo } \\
194\end{array}$ & & & \\
\hline
\end{tabular}


Justicia

Derechos de las víctimas con énfasis en las mujeres/Reglamentación correspondiente
Responsabilidad

de la entidad territorial
Variables para la caracterización de las mujeres y niñas víctimas
Preguntas guía para la caracterización

\begin{tabular}{|c|c|c|c|c|}
\hline $\begin{array}{l}\text { Información de } \\
\text { asesoría y apoyo. } \\
\text { Las entidades que } \\
\text { brinden apoyo } \\
\text { deberán contar } \\
\text { con personal } \\
\text { capacitado para } \\
\text { en atención } \\
\text { de víctimas de } \\
\text { violencia sexual y } \\
\text { género. }\end{array}$ & $\begin{array}{c}\text { Ley } 1448 \\
\text { de } 2011^{-} \\
\text {Artículo } \\
\text { 35. Decreto } \\
4800 \\
\text { de } 2011^{-} \\
\text {Artículo } 85\end{array}$ & $\begin{array}{l}\text { Promover el conocimiento de } \\
\text { la ruta y la información que } \\
\text { requieran las víctimas y que le } \\
\text { sean útiles durante el proceso } \\
\text { judicial. }\end{array}$ & $\begin{array}{l}\text { Población } \\
\text { femenina }\end{array}$ & $\begin{array}{l}\text { Escribir nuevamente las pre- } \\
\text { guntas de caracterización. }\end{array}$ \\
\hline $\begin{array}{l}\text { Principios de la } \\
\text { prueba en casos } \\
\text { de violencia } \\
\text { sexual }\end{array}$ & $\begin{array}{c}\text { Ley } 1448 \\
\text { de 2011- } \\
\text { Artículo } 38\end{array}$ & & $\begin{array}{l}\text { Violencia contra } \\
\text { las mujeres }\end{array}$ & $\begin{array}{l}\text { Escribir nuevamente las pre- } \\
\text { guntas de caracterización. }\end{array}$ \\
\hline $\begin{array}{l}\text { Testimonio } \\
\text { por medio de } \\
\text { audio o video. La } \\
\text { autoridad tiene } \\
\text { la obligación } \\
\text { de garantizar } \\
\text { la seguridad } \\
\text { y los medios } \\
\text { necesarios para } \\
\text { rendir testimonio } \\
\text { cuando se trate } \\
\text { de niños, niñas y } \\
\text { adolescentes. }\end{array}$ & $\begin{array}{c}\text { Ley } 1448 \\
\text { de } 2011^{-} \\
\text {Artículo } \\
\quad 40\end{array}$ & & $\begin{array}{l}\text { Acceso a } \\
\text { vivienda y } \\
\text { tierras }\end{array}$ & $\begin{array}{l}\text { Escribir nuevamente las pre- } \\
\text { guntas de caracterización. }\end{array}$ \\
\hline $\begin{array}{l}\text { Modalidad } \\
\text { especial de } \\
\text { testimonio. El } \\
\text { juez o magistrado } \\
\text { decretar medidas } \\
\text { especiales } \\
\text { para facilitar el } \\
\text { testimonio de } \\
\text { niños, niñas y } \\
\text { adolescentes y } \\
\text { de víctimas de } \\
\text { violencia sexual. }\end{array}$ & $\begin{array}{l}\text { Ley } 1448 \\
\text { de } 2011^{-} \\
\text {Artículo } 41\end{array}$ & & & \\
\hline $\begin{array}{l}\text { Presencia } \\
\text { de personal } \\
\text { especializado. }\end{array}$ & $\begin{array}{l}\text { Ley } 1448 \\
\text { de } 2011- \\
\text { Artículo } 42\end{array}$ & & & \\
\hline
\end{tabular}


Retornos y Reubicaciones

Derechos de las víctimas con énfasis en las mujeres/Reglamentación correspondiente
Responsabilidad de la entidad territorial
Variables para la caracterización de las mujeres y niñas víctimas
Preguntas guía para la caracterización

\begin{tabular}{|c|c|c|c|c|}
\hline \multirow[t]{5}{*}{$\begin{array}{l}\text { Retornos y } \\
\text { Reubicaciones }\end{array}$} & \multirow{5}{*}{$\begin{array}{c}\text { Ley } 1448 \\
\text { de } 2011- \\
\text { Artículo } \\
66 . \\
\text { Decreto } \\
4800 \\
\text { de } 2011- \\
\text { Artículo } \\
71,72\end{array}$} & \multirow{5}{*}{$\begin{array}{l}\text { Acciones de coordinación, pla- } \\
\text { neación, seguimiento y parti- } \\
\text { cipación de víctimas incluidas } \\
\text { en los procesos de retorno o } \\
\text { reubicación. (Decreto } 4800 \text { de } \\
2011 \text { - Artículo } 75 \text { y } 76 \text { ). } \\
\text { Elaboración de los planes de re- } \\
\text { tornos y reubicaciones. (Decre- } \\
\text { to } 4800 \text { de } 2011 \text { - Artículo } 76 \text { ). } \\
\text { Evaluacióny complementación } \\
\text { delas condiciones de seguridad } \\
\text { en operaciones de retornos y } \\
\text { reubicaciones emitidas por la } \\
\text { Fuerza Pública. }\end{array}$} & $\begin{array}{l}\text { Población } \\
\text { femenina }\end{array}$ & $\begin{array}{l}\text { Escribir nuevamente las pre- } \\
\text { guntas de caracterización }\end{array}$ \\
\hline & & & $\begin{array}{c}\text { Autonomía } \\
\text { económica: } \\
\text { informalidad } \\
\text { laboral y } \\
\text { desempleo. }\end{array}$ & $\begin{array}{l}\text { Escribir nuevamente las pre- } \\
\text { guntas de caracterización }\end{array}$ \\
\hline & & & Salud integral: & $\begin{array}{l}\text { Escribir nuevamente las pre- } \\
\text { guntas de caracterización }\end{array}$ \\
\hline & & & Educación & $\begin{array}{l}\text { Escribir nuevamente las pre- } \\
\text { guntas de caracterización }\end{array}$ \\
\hline & & & $\begin{array}{l}\text { Violencia contra } \\
\text { las mujeres }\end{array}$ & $\begin{array}{l}\text { Escribir nuevamente las pre- } \\
\text { guntas de caracterización }\end{array}$ \\
\hline
\end{tabular}


Participación

Derechos de las víctimas con énfasis en las mujeres/Reglamentación correspondiente
Responsabilidad de la entidad territorial
Variables para la caracterización de las mujeres y niñas víctimas
Preguntas guía para la caracterización

\begin{tabular}{|c|c|c|c|c|}
\hline Participación & $\begin{array}{c}\text { Ley } 1448 \\
\text { de } 2011- \\
\text { Artículo } \\
193 . \\
\text { Decreto } \\
4800 \\
\text { de } 2011- \\
\text { Artículo } \\
261\end{array}$ & \multirow{3}{*}{$\begin{array}{l}\text { Apoyar técnica, logística y fi- } \\
\text { nancieramente los procesos } \\
\text { de inscripción de las Organi- } \\
\text { zaciones de Víctimas, la con- } \\
\text { formación de las Mesas de } \\
\text { Participación y que las Mesas } \\
\text { de Participación de las Víctimas } \\
\text { brinden insumos para el dise- } \\
\text { ño, planificación y seguimiento } \\
\text { de la política pública. (Decreto } \\
\text { 48oo de 2011- Artículo 262). } \\
\text { Las mesas municipales, distri- } \\
\text { tales y departamentales y los } \\
\text { Comités Territoriales de Jus- } \\
\text { ticia Transicional serán espa- } \\
\text { cios de participación efectiva } \\
\text { de las víctimas. (Decreto } 4800 \\
\text { de } 2011-\text { Artículo 263). }\end{array}$} & $\begin{array}{l}\text { Población } \\
\text { femenina }\end{array}$ & $\begin{array}{l}\text { Escribir nuevamente las pre- } \\
\text { guntas de caracterización. }\end{array}$ \\
\hline $\begin{array}{l}\text { Espacios de } \\
\text { participación }\end{array}$ & $\begin{array}{c}\text { Decreto } \\
4800 \\
\text { de } 2011- \\
\text { Artículo } \\
263\end{array}$ & & $\begin{array}{l}\text { Participación } \\
\text { Política }\end{array}$ & \multirow[t]{2}{*}{$\begin{array}{l}\text { a. ¿Pertenece usted a alguna } \\
\text { agrupación? } \\
\text { b. ¿Es usted líder de alguna } \\
\text { comunidad/grupo u organi- } \\
\text { zación? } \\
\text { c. ¿Le interesaría participar en } \\
\text { política? }\end{array}$} \\
\hline $\begin{array}{l}\text { Mesas de } \\
\text { participación. } \\
\text { Estas deben } \\
\text { garantizar la } \\
\text { participación } \\
\text { efectiva de las } \\
\text { mujeres. }\end{array}$ & $\begin{array}{c}\text { Decreto } \\
4800 \\
\text { de } 2011- \\
\text { Artículo } \\
264\end{array}$ & & & \\
\hline
\end{tabular}


Protección Integral a Niñas y Adolescentes

Derechos de las víctimas con énfasis en las mujeres/Reglamentación correspondiente
Responsabilidad de la entidad territorial
Variables para la caracterización de las mujeres y niñas víctimas
Preguntas guía para la caracterización

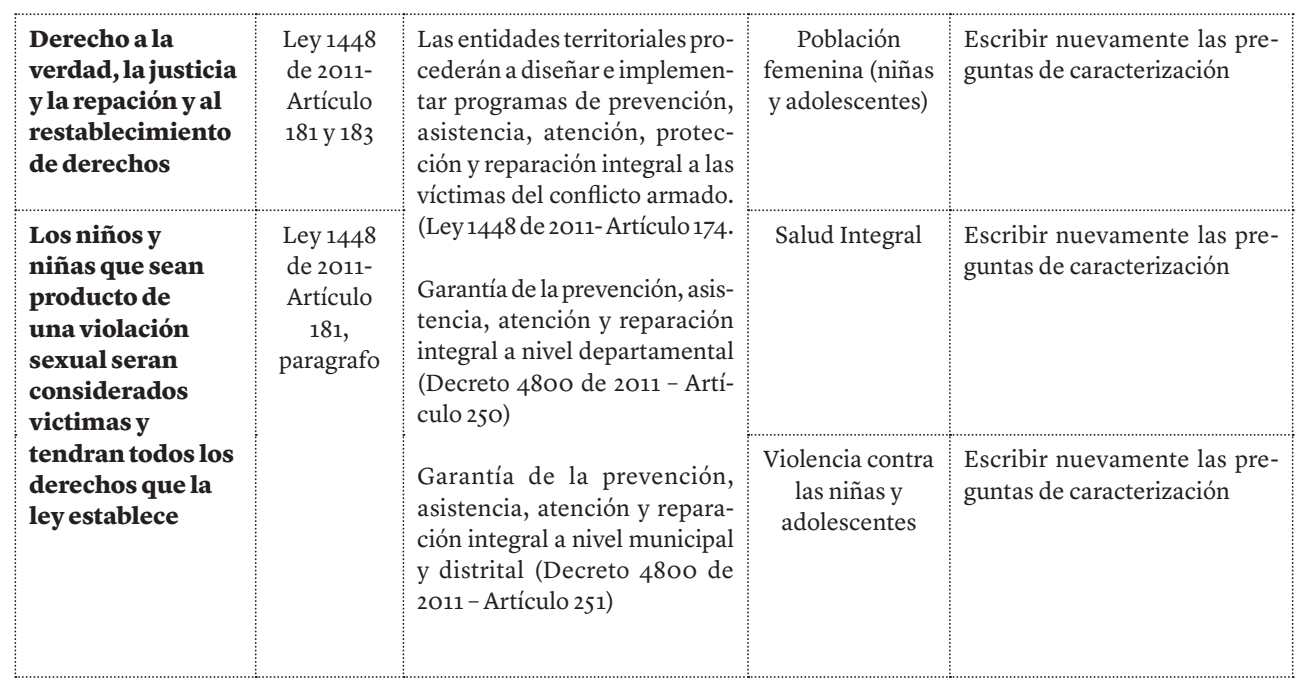

